\title{
Juan de Fuca slab geometry and its relation to Wadati-Benioff zone seismicity
}

\author{
Patricia A. McCrory, ${ }^{1}$ J. Luke Blair, ${ }^{1}$ Felix Waldhauser, ${ }^{2}$ and David H. Oppenheimer ${ }^{1}$
}

Received 1 May 2012; revised 17 July 2012; accepted 19 July 2012; published 18 September 2012.

[1] A new model of the subducted Juan de Fuca plate beneath western North America allows first-order correlations between the occurrence of Wadati-Benioff zone earthquakes and slab geometry, temperature, and hydration state. The geo-referenced 3D model, constructed from weighted control points, integrates depth information from earthquake locations and regional seismic velocity studies. We use the model to separate earthquakes that occur in the Cascadia forearc from those that occur within the underlying Juan de Fuca plate and thereby reveal previously obscured details regarding the spatial distribution of earthquakes. Seismicity within the slab is most prevalent where the slab is warped beneath northwestern California and western Washington suggesting that slab flexure, in addition to expected metamorphic dehydration processes, promotes earthquake occurrence within the subducted oceanic plate. Earthquake patterns beneath western Vancouver Island are consistent with slab dehydration processes. Conversely, the lack of slab earthquakes beneath western Oregon is consistent with an anhydrous slab. Double-differenced relocated seismicity resolves a double seismic zone within the slab beneath northwestern California that strongly constrains the location of the plate interface and delineates a cluster of seismicity $10 \mathrm{~km}$ above the surface that includes the 1992 M7.1 Mendocino earthquake. We infer that this earthquake ruptured a surface within the Cascadia accretionary margin above the Juan de Fuca plate. We further speculate that this earthquake is associated with a detached fragment of former Farallon plate. Other subsurface tectonic elements within the forearc may have the potential to generate similar damaging earthquakes.

Citation: McCrory, P. A., J. L. Blair, F. Waldhauser, and D. H. Oppenheimer (2012), Juan de Fuca slab geometry and its relation to Wadati-Benioff zone seismicity, J. Geophys. Res., 117, B09306, doi:10.1029/2012JB009407.

\section{Introduction}

[2] The oceanic Juan de Fuca (JdF) plate underthrusts the continental North American plate along the Cascadia subduction boundary. Convergence rates along the plate boundary range from $30 \mathrm{~mm} / \mathrm{y}$ at its southern end to $45 \mathrm{~mm} / \mathrm{y}$ at its northern end [Wilson, 1993], driving earthquake occurrence within the two tectonic plates as well as prehistoric earthquake occurrence along the plate interface. An accurate map of the Cascadia subduction boundary beneath northern California, Oregon, Washington, and southern British Columbia is essential for assessments of these earthquake sources.

[3] Most active subduction boundaries have ubiquitous background earthquakes which illuminate the geometry of the subduction margin. For these subduction boundaries, spatial and temporal earthquake patterns allow examination

\footnotetext{
${ }^{1}$ U.S. Geological Survey, Menlo Park, California, USA.

${ }^{2}$ Lamont-Doherty Earth Observatory, Earth Institute at Columbia University, Palisades, New York, USA.

Corresponding author: P. A. McCrory, U.S. Geological Survey, 345 Middlefield Rd., Menlo Park, CA 94025, USA. (pmccrory@usgs.gov)

(C)2012. American Geophysical Union. All Rights Reserved. 0148-0227/12/2012JB009407
}

of variations in dynamic subduction processes. Such studies are able to use Wadati-Benioff zone (WBZ) seismicity to map the location of the subducted oceanic plate (slab) by assuming that the uppermost WBZ earthquakes occur within slab crust 6 to $10 \mathrm{~km}$ thick.

[4] The Cascadia subduction boundary lacks widespread earthquakes in both the forearc region of the North American plate and in the subducting Juan de Fuca plate. In particular, WBZ seismicity occurs mainly in three areas: at shallow depths beneath western Vancouver Island and beneath northwestern California, and at intermediate depths beneath Strait of Georgia-Puget Sound (Figure 1). Furthermore, WBZ seismicity rarely extends deeper than $40 \mathrm{~km}$. While valuable, these earthquakes are not sufficient to map the geometry of the entire plate boundary. The scarcity of earthquakes impedes our ability to track subduction processes typically associated with seismicity, such as dehydration and densification of the subducting oceanic plate, pathways and barriers to movement of geo-fluids released during dehydration, and three dimensional (3D) structural complexities within both the forearc and the subducting plate. Thus, for Cascadia, constructing a laterally continuous 3D model of the subducting plate requires integration of active and passive source seismic velocity data and seismic reflection data with $\mathrm{WBZ}$ seismicity. 


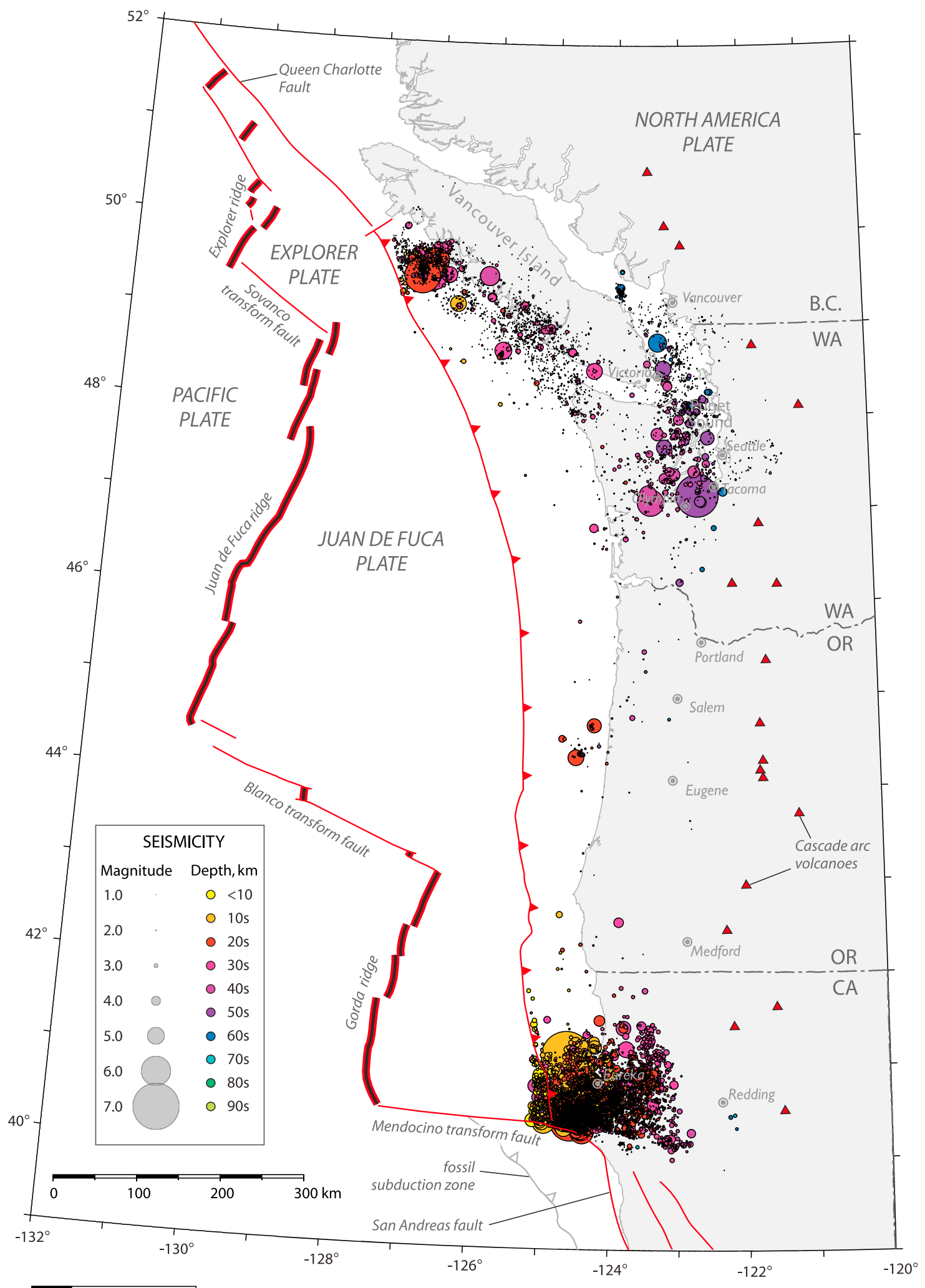

GMT2 2010 Jul 15 12:21:54

Figure 1. Location map showing uneven distribution of epicenters interpreted to be Wadati-Benioff earthquakes beneath the Cascadia subduction boundary colored by depth range. Earthquakes compiled from ANSS (1975-2009) and CNSN (1985-2009) catalogs based on Juan de Fuca slab model shown in Figure 4a. Transverse Mercator projection, WGS 84 standard parallel $-128^{\circ}$, centered at $46.8^{\circ},-128^{\circ}$, with standard parallel rotated $3^{\circ}$ clockwise of vertical (plate boundaries from Wilson [2002]). 
Table 1. Data Types, With Citations, Used to Constrain Depth to Juan de Fuca Slab Model

\begin{tabular}{|c|c|}
\hline Data Type & Reference \\
\hline Network seismicity & $\begin{array}{l}\text { Crosson and Owens [1987], Graindorge et al. [2003], Hyndman et al. [1990], } \\
\quad \text { Nedimović et al. [2003] }\end{array}$ \\
\hline ANSS Catalog, CNSN Catalog & This study \\
\hline hypoDD seismicity & Cassidy and Waldhauser [2003], (http://www.ldeo.columbia.edu/ felixw/NCAeqDD/200812/) \\
\hline Active source velocity models & $\begin{array}{l}\text { Beaudoin et al. [1998], Brocher et al. (1994; } 1996 \text { unpublished data), } \\
\text { Calvert et al. [2003, 2006], Clowes et al. [1987], Creager et al. [2002], } \\
\text { Flueh et al. [1998], Gerdom et al. [2000], Graindorge et al. [2003], } \\
\text { Henstock and Levander [2003], Hyndman et al. [1990], Keach et al. [1989], } \\
\text { Nedimović et al. [2003], Parsons et al. [1999], Pecher et al. (1996 unpublished data), } \\
\text { Preston et al. [2003], Ramachandran et al. [2005, 2006], Tréhu et al. [1994] }\end{array}$ \\
\hline Passive source velocity models & $\begin{array}{l}\text { Audet et al. [2010], Bostock et al. [2002], Calvert et al. [2011], Cassidy [1995], } \\
\text { Cassidy and Waldhauser [2003], Crosson and Owens [1987], Harris et al. [1991], } \\
\text { Michaelson and Weaver [1986], Nabelek et al. [1993], Nicholson et al. [2005] }\end{array}$ \\
\hline Resistivity profiles & Kurtz et al. [1986]; Wannamaker et al. [1989] \\
\hline
\end{tabular}

\subsection{Previous Work}

[5] Flück et al. [1997] constructed a generalized model of the Cascadia plate boundary down to $50 \mathrm{~km}$ depth in order to examine strain accumulation and release along the subduction boundary. Their model is based, in part, on seismic velocity structure depicted in four active source transects. McCrory et al. [2006] subsequently updated the Flück et al. model and extended it down to $90 \mathrm{~km}$ based, in part, on seismic velocity structure derived from two more recent regional, active source experiments: SHIPS in the Strait of Georgia-Puget Sound region and MTJ in northern California. Slab depths derived from these experiments were supplemented with hypocenters recorded by the Northern California Seismic System (NCSS) and the Pacific Northwest Seismic Network (PNSN), newly acquired verticalincidence, multichannel seismic reflection (MCS) profiles, wide-angle seismic reflection and refraction profiles, and a resistivity profile. McCrory et al. [2006] constructed a georeferenced plate boundary model in order to examine $3 \mathrm{D}$ spatial and temporal earthquake patterns occurring within the slab and overlying forearc. More recently, Audet et al. [2010] constructed a model depicting the depth to the JdF slab surface between 20 and $40 \mathrm{~km}$ in order to examine episodic tremor and slip (ETS) phenomena. The Audet et al. model is based primarily on $S$ wave amplitude perturbations derived from analysis of teleseismic receiver function data.

\subsection{Motivation for Update}

[6] We build on these previous results with additional hypocenter data and seismic velocity models to construct a more detailed model of JdF slab geometry beneath the Cascadia subduction margin. The previous McCrory et al. [2006] model was constructed by modifying the Flück et al. [1997] model where additional depth information was available. The current version contours depth control points with no inherited slab geometry, a significantly different modeling approach warranted by a substantial increase in available depth information. In particular, a new catalog of doubledifferenced (hypoDD) hypocenter relocations for northern California [Waldhauser and Schaff, 2008] (http://www.ldeo. columbia.edu/ felixw/NCAeqDD/200812) allows us to supplement previous depth control data and better resolve slab geometry at the southern end of the Cascadia subduction zone. Slab geometry had been poorly defined and overly simplified in the Mendocino triple junction (intersection of Pacific, North American, and JdF plates) region owing to its complex tectonic structure. In particular, network-located hypocenters formed a diffuse cloud, obscuring the subduction interface between the upper and lower plates. The substantial catalog of relocated NCSS earthquakes in northern California (1984-2008; http://www.ldeo.columbia.edu/ felixw/NCAeqDD/200812) enables us to map slab geometry in this complex region more accurately. Furthermore, our new model incorporates an additional 7 years of network seismicity data of particular importance in Oregon, Washington, and British Columbia where seismicity is notably sparse.

[7] Whereas no new active source experiments have been conducted since our previous model was constructed in 2003, the newer seismic velocity studies we have incorporated into this model employ more advanced modeling schemes than were previously available. In the Vancouver IslandWashington region, we utilize several two- and three-dimensional $P$ wave seismic velocity models which simultaneously invert teleseismic and regional earthquakes with re-processed active source data (Table 1). Slab geometry is complicated in this region and these more comprehensive studies supplement and, in some cases, supplant previous models of seismic velocity structure.

[8] By offering a straightforward means to separate WBZ earthquakes from forearc earthquakes, the new model provides a valuable tool not only for examination of spatial and temporal seismicity patterns within the slab and the overlying forearc, but also for investigation of parameters that promote or suppress the occurrence of earthquakes, slow-slip events, and non-volcanic tremor. Furthermore, this model provides an updated reference surface for new research based on Cascadia GeoPRISMS investigations.

\section{Methods}

\subsection{Data Used in New Model}

[9] With our focus on spatial and temporal earthquake patterns, we rely primarily on WBZ hypocenters to map the location of the slab. Where these data are sparse such as beneath Oregon or poorly located such as offshore, we rely on published profiles of seismic velocity structure to map slab depth, supplemented with marine seismic reflection profiles. 
[10] In our analysis we consider the Cascadia subduction boundary to be located at the top of JdF igneous crust (top of Layer 2), but this may not be entirely accurate. For some subduction zones the interface where relative plate motion is concentrated may reside in accreted or subducted oceanic sediments above the slab or span a shear zone (e.g., Sumatran subduction interface [Dean et al., 2010]). Thus, the JdF slab surface may diverge from the actual subduction interface by a few kilometers.

[11] We have constructed two JdF slab models from 37 hypocenter profiles (19 from Advanced National Seismic System (ANSS) earthquake catalog; 2 from Canadian National Seismograph Network (CNSN) earthquake catalog; 2 that cross the Canada-U.S. border and combine CNSN and ANSS earthquake data; 14 from hypoDD relocations of NCSS earthquake data), $52 P$ wave velocity profiles (derived from wide-angle seismic reflection or refraction data, or from vertical-incidence, MCS data) including 5 unpublished profiles, $9 S$ wave velocity or amplitude perturbation profiles and 2 single points (derived from teleseismic receiver function data), and 2 resistivity profiles (Table 1; locations shown in Figures S2, S4, and S5 in the auxiliary material). ${ }^{1}$ We utilize 35 years (1975-2009) of recorded earthquakes from the ANSS catalog, filtered to be consistent with the 25 years (1984-2008) of relocated NCSS catalog earthquakes. Specifically, we retained earthquakes recorded at a minimum of 6 stations, with locations having a maximum RMS of $0.5 \mathrm{~s}$, between depths of $0-150 \mathrm{~km}$ and ranging in magnitude from 0 to $7+$. In addition, we eliminated events whose formal vertical (depth) error was $10 \mathrm{~km}$ or greater (Figure 2). The formal error estimates provided in network catalogs likely underestimate the true location error, especially for areas with sparse network seismograph coverage. Similar station, RMS, and vertical error data were not available for the 25 years (1985-2009) of CNSN data utilized in this study. For CNSN data, all events were incorporated into two Canadian and two cross-border Canadian-U.S. profiles.

[12] $P$ wave velocity data generally do not resolve subduction-related features deeper than $50 \mathrm{~km}$ [e.g., Ramachandran et al., 2006]. Where the slab is deeper such as beneath Puget Sound, we rely on a few velocity profiles derived from very wide-angle refraction data. Verticalincidence seismic reflection data are generally restricted to depths shallower than $40 \mathrm{~km}$ [e.g., Nedimović et al., 2003]. These marine seismic reflection profiles are typically sufficient to map the slab surface beneath the continental shelf. However, the older profiles do not typically delineate the plate interface beneath the continental slope owing to the difficulty of resolving complex seismic structures within the overlying accretionary prism [e.g., Hyndman et al., 1990] with MCS data acquired from relatively short hydrophone streamers $(\leq 3 \mathrm{~km})$ and processed with older imaging methodology. Where vertical-incidence seismic reflection profiles are lacking, we pin the location of the oceanic plate at $5 \mathrm{~km}$ depth where it enters the trench and interpolate a smooth curve arc-ward. This generalized estimate includes water depth plus the thickness of sediment overlying the slab and has an uncertainty of about $1 \mathrm{~km}$.

\footnotetext{
${ }^{1}$ Auxiliary material data sets are available at $\mathrm{ftp}: / / \mathrm{ftp}$.agu.org/apend/jb/ 2012jb009407. Other auxiliary material files are in the HTML. doi:10.1029/2012JB009407.
}

[13] Models based on $S$ wave data generally depict velocity perturbations about a specified mean value rather than actual velocities. Some of these velocity models can extend quite deep, deeper than $100 \mathrm{~km}$ along some profiles (e.g., Bostock et al. [2002]; albeit with constant dip extrapolated below $60 \mathrm{~km})$. Profiles depicting $S$ wave amplitude perturbations resolve subduction-related features between 20 and $40 \mathrm{~km}$ depth [Audet et al., 2010].

[14] For hypocenter profiles we generally infer the top of the JdF slab to be near the upper surface of WBZ seismicity. For $P$ wave velocity profiles we infer the top of the slab to be $7 \mathrm{~km}$ above the sharp velocity gradient interpreted as the Mohorovičić discontinuity (Moho) within oceanic lithosphere [Clowes et al., 1987; Nedimović et al., 2005]. $S$ wave velocity studies generally interpret a thin low velocity layer (LVZ) to be slab crust and we map the top of the slab along its upper surface. The top of the slab in resistivity profiles is correlated with the base of a thin dipping conductor interpreted to represent fluids trapped above the slab surface [e.g., Wannamaker et al., 1989]. Depth control derived from the entire set of 102 profiles (plus 2 points) results in about 800 data points, dense in some locations, sparse in others (Figure 3). These points are geo-referenced in terms of latitude, longitude, and depth with respect to sea level. Even with this large data set, mapping the slab surface remains challenging owing to the uneven distribution of depth control and discrepancies in depth assignments between various publications.

[15] The variability of depth assignments between adjacent points in regions with dense depth control is problematic. These discrepancies occur even between contemporaneous studies modeling similar data sets. To address this variability we developed a scheme that assigns weights to control points based on data uncertainties associated with delineating the slab location (Table S1 in the auxiliary material). Seismicity data are generally given the highest weight since we specifically use the model to examine seismicity patterns, consistent with how many slab models around the Pacific Rim have been constructed [e.g., Gutscher et al., 2000b; Reyners and Eberhart-Phillips, 2009; Hayes et al., 2012]. Active source data are generally given the next highest weight since these are the next most abundant data set and serve to complement the seismicity data where earthquakes are sparse. $S$ wave profiles based on passive source data are generally given a lower weight as depths derived from these data tend to diverge significantly from both the seismicity and active source data, causing large 'ripples' or corrugations in the isodepth contours. Thus, the weighting scheme results in a de facto choice between seismic velocity models.

\subsection{Modeling Approach}

[16] We used two different methods to construct slab geometry. The first method employed hand contouring of weighted control points (Figures $4 \mathrm{a}$ and $4 \mathrm{~b}$ ) an approach similar to our previous model [McCrory et al., 2006]. This version was designed primarily as a tool to separate earthquakes above and below the slab surface, and thus conforms closely to apparent warps and buckles in the slab.

[17] The second method employed polynomial splines of the same set of weighted control points to calculate the location of the slab surface. The computer-generated version was partly intended to serve as a check for subjectivity in the 


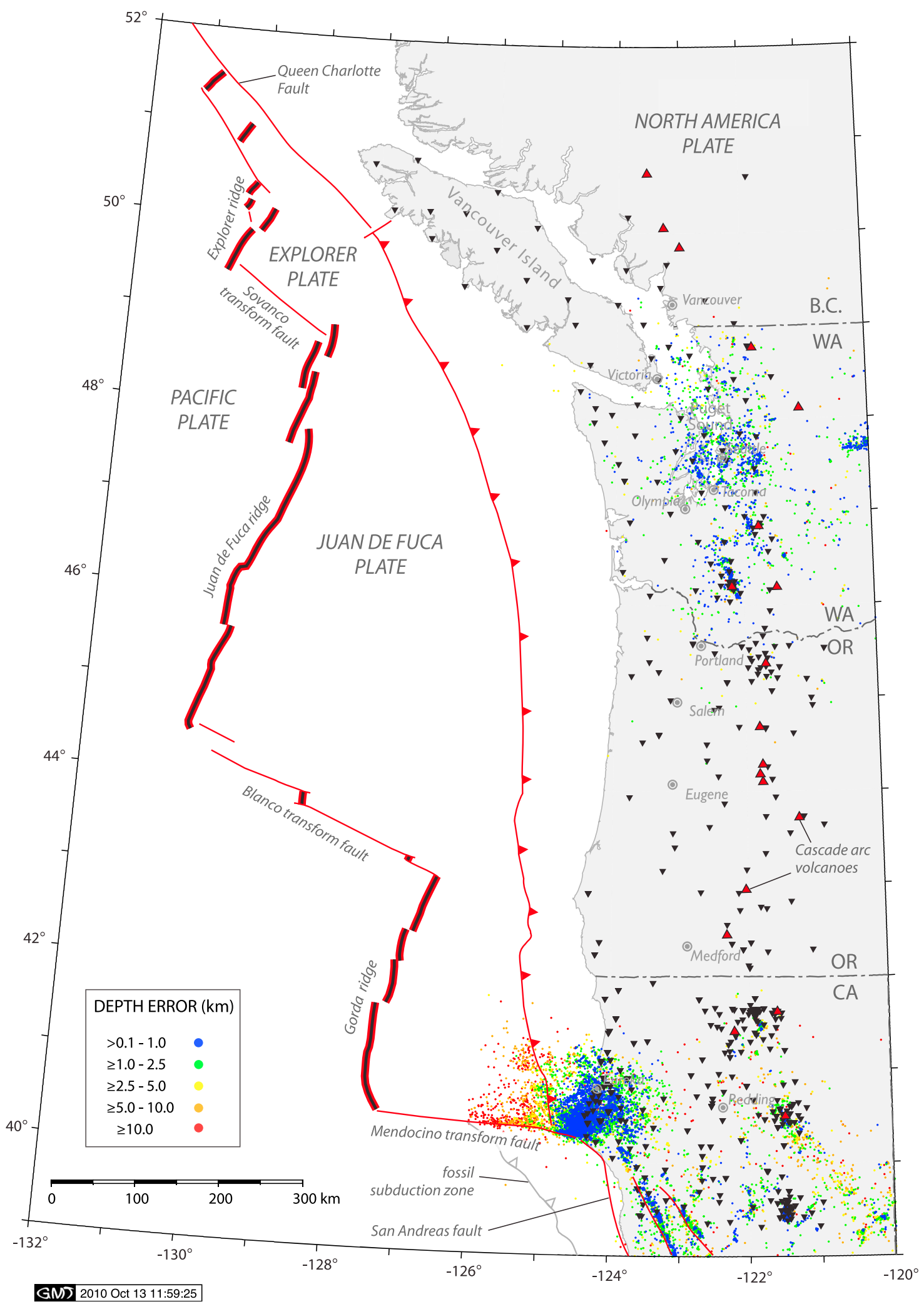

Figure 2. Map showing ANSS Wadati-Benioff epicenters colored by depth error (depth error data not available for CNSN catalog). Current ANSS and CNSN seismograph stations denoted by inverted black triangles. (See Figure 1 for base map notes.) 


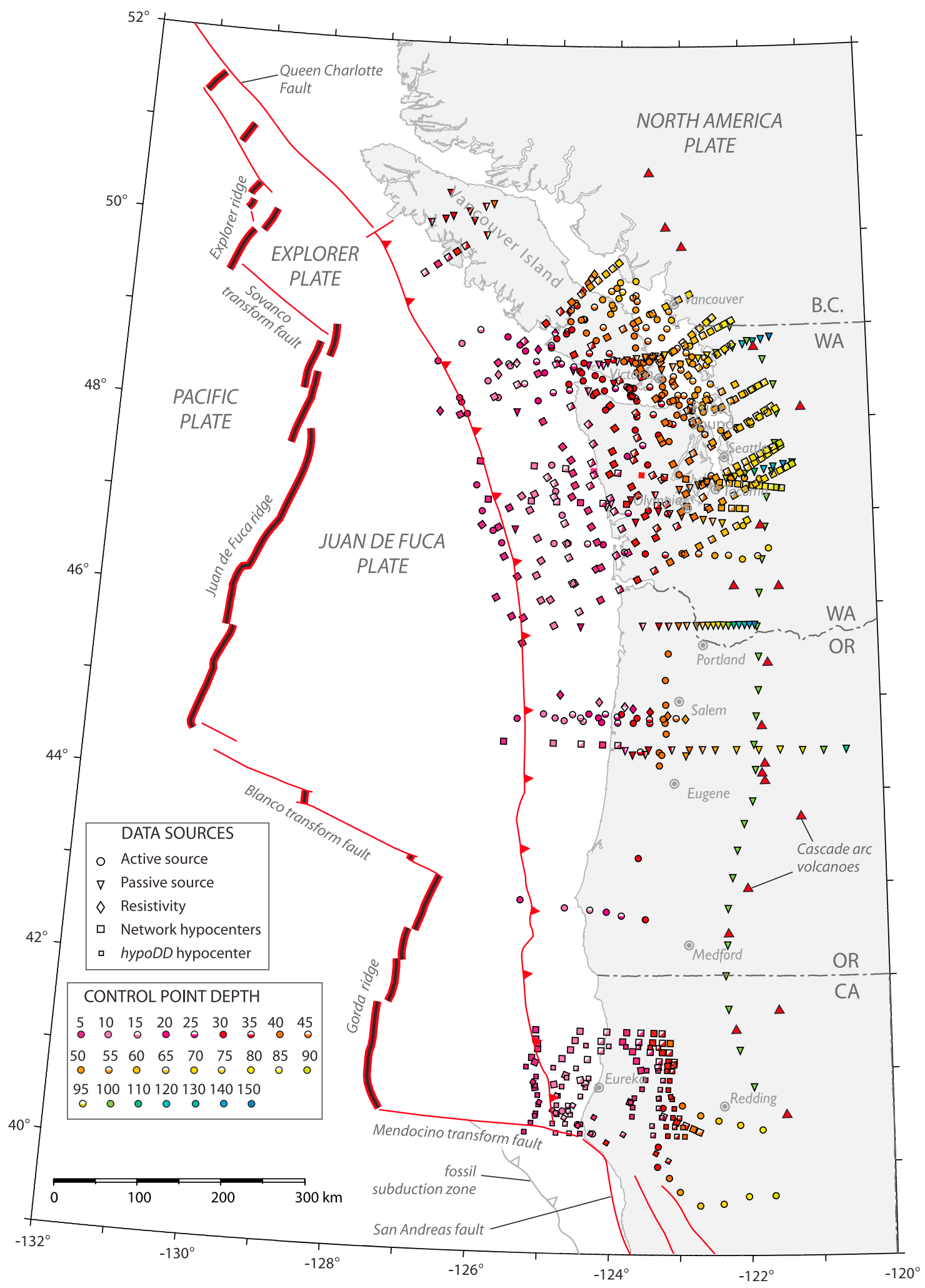

Figure 3. Map showing uneven distribution of control points used to constrain the depth of the Juan de Fuca slab (see text for discussion; see Figure 1 for base map notes). 


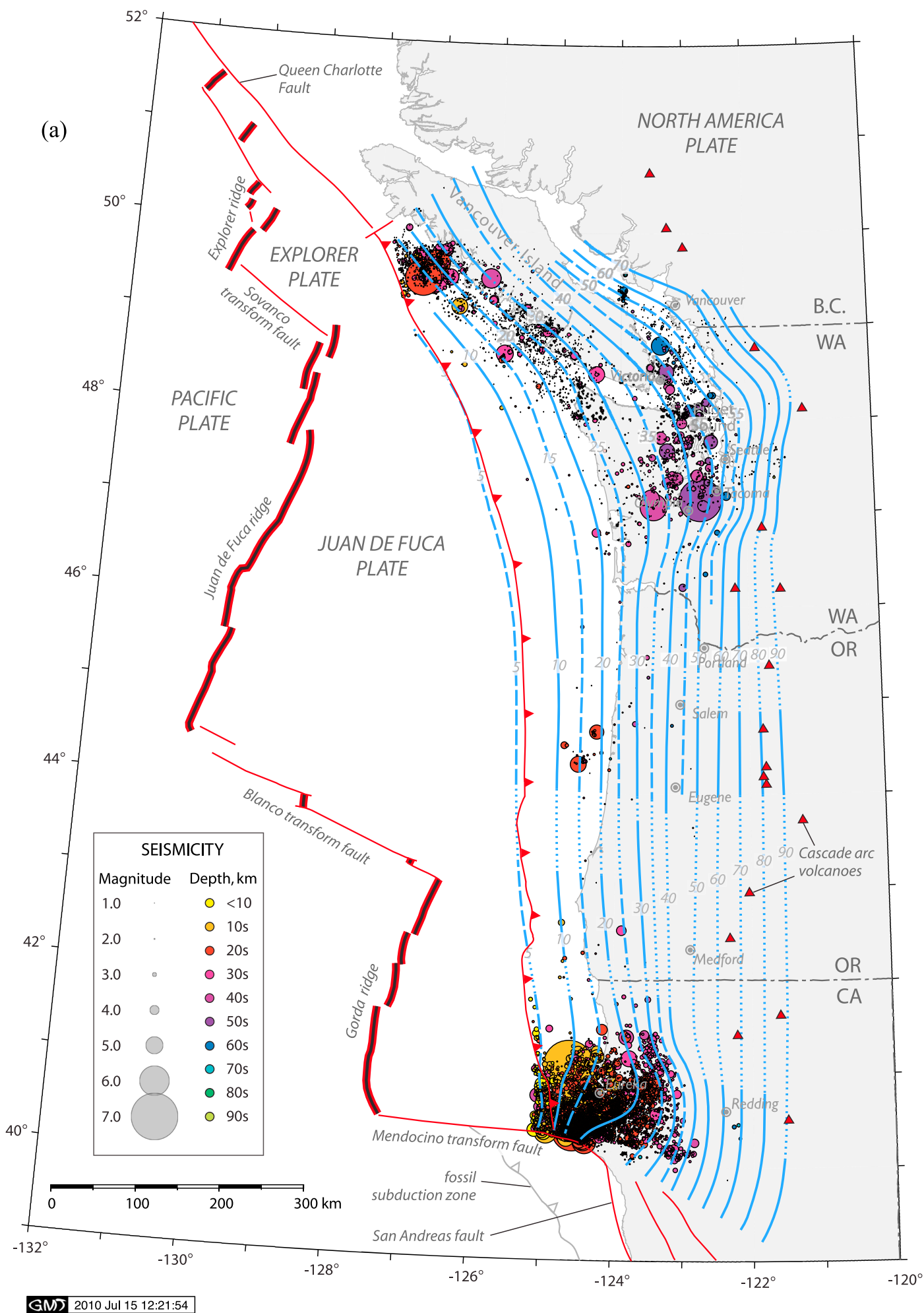

Figure 4. (a) Map showing hand-contoured model of the Juan de Fuca slab surface (see text for description) and seismicity (ANSS, 1975-2009; CNSN, 1985-2009) located beneath the modeled surface. Solid lines denote depth contours in $10 \mathrm{~km}$ increments, long dashed lines denote supplemental depth contours in $5 \mathrm{~km}$ increments; short dashed lines denote interpolated contours where control points are more than $50 \mathrm{~km}$ apart. Note that Wadati-Benioff zone seismicity mainly occurs in regions where slab model arches along strike. (b) Map showing hand-contoured model the Juan de Fuca slab surface and seismicity located in the Cascadia forearc above the slab surface. (c) Map showing smoothed polynomial spline version of slab model. Solid lines denote depth contours in $10 \mathrm{~km}$ increments; long dashed lines denote supplemental depth contours in $5 \mathrm{~km}$ increments; short dashed lines denote extrapolated contours. (See Figure 1 for base map notes.) 


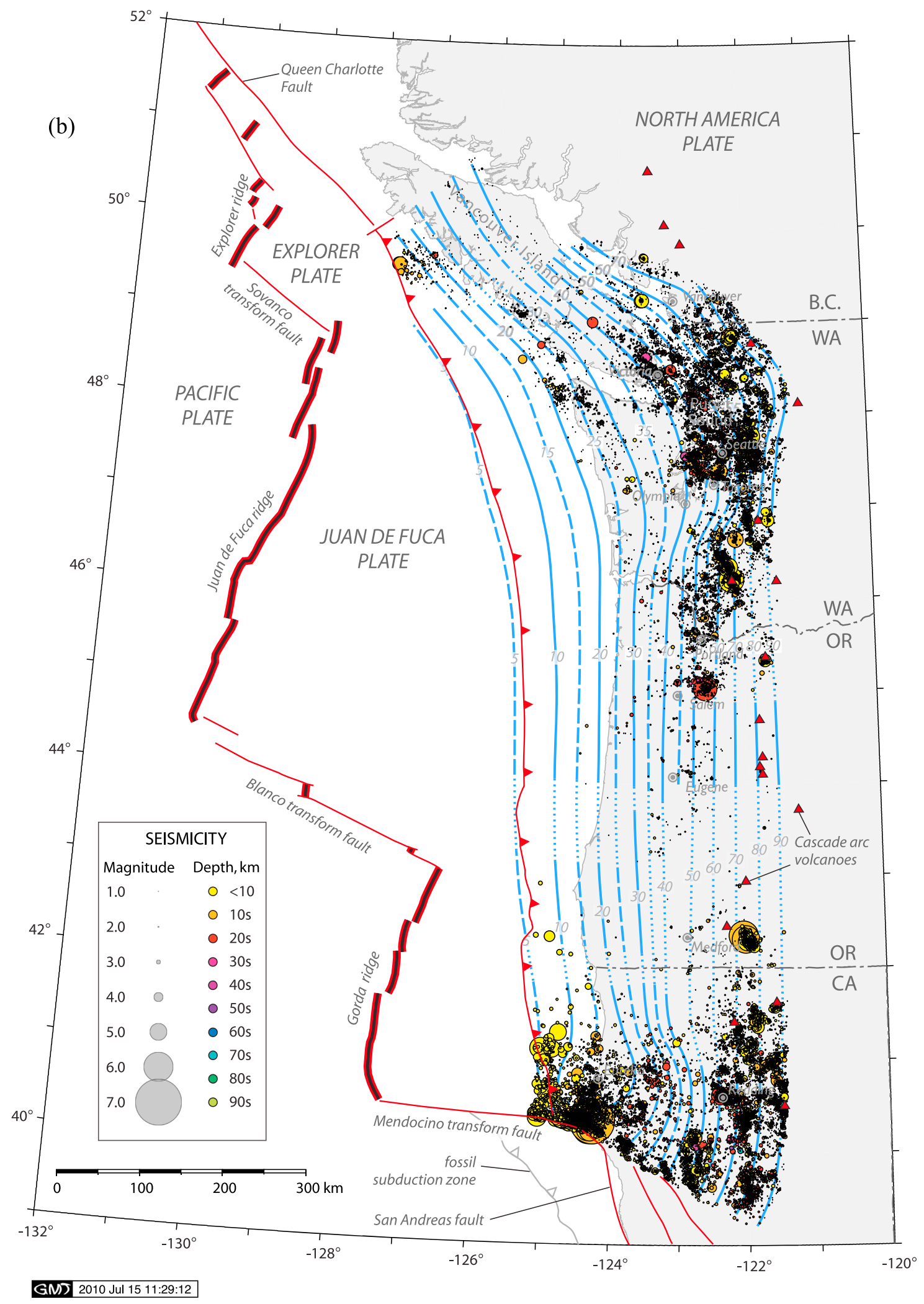

Figure 4. (continued) 


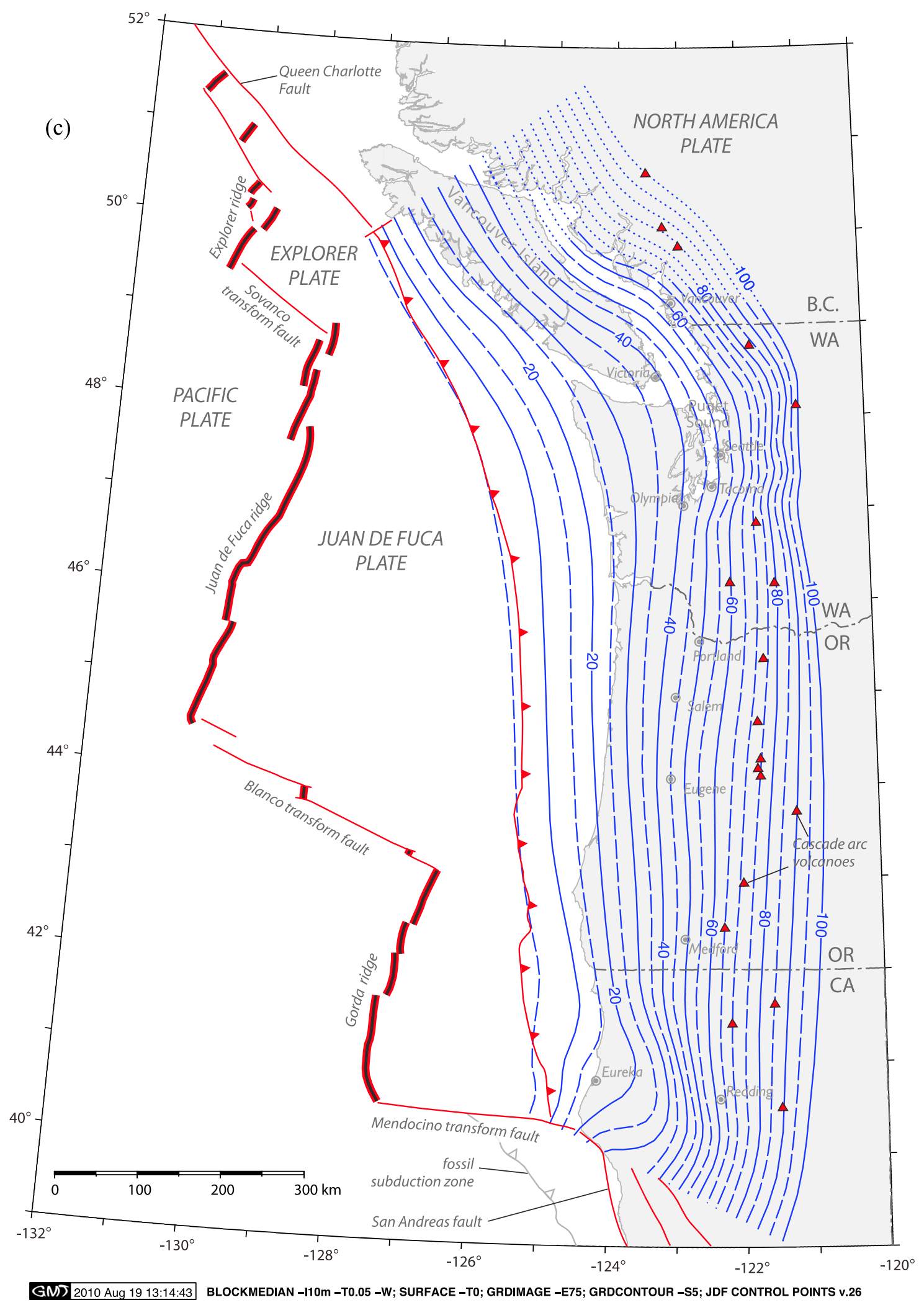

Figure 4. (continued) 
hand-generated version. For example, the kink in slab contours just south of Puget Sound persists in the computergenerated version of the slab (Figure 4c), thus cannot be attributed to subjective contouring of the depth control points. Likewise, the flat slab beneath northern California persists in the computer-generated version.

[18] The computer-generated slab model is based on a $10 \mathrm{~min}$ grid constructed from the geo-referenced control points and contoured using the GMT Surface script [Wessel and Smith, 1998] which interpolates and grids clustered, noisy, 3D data using Green's functions for splines-in-tension to reduce artifacts [Wessel and Bercovici, 1998]. We conducted dozens of polynomial spline modeling runs, varying parameters and subsets of data to ascertain their effects on the shape of the slab surface. Although the final GMT version replicates the general shape of the hand-contoured version, it also contains obvious distortions owing primarily to the uneven distribution of data points (Figure S1 in the auxiliary material). Therefore, we constructed a third version derived from the GMT contours that smoothes these distortions to provide a simplified contour map of the slab (compare Figures $4 \mathrm{c}$ and $\mathrm{S} 1$ in the auxiliary material) suitable for investigations which require a simpler surface to model strain, stress, ETS, and other phenomena associated with the Cascadia subduction boundary.

\subsection{Comparison With Previous Model}

[19] Our new slab model differs from the previous one in a number of key areas (Figure 5a). We only extrapolate contours of the new hand-contoured model for $50 \mathrm{~km}$ past available depth control and we indicate where contours are interpolated between widely spaced $(>100 \mathrm{~km})$ control points. These two refinements are most noticeable for northern Vancouver Island where previous contours had been extrapolated with uniform dip northward from control points beneath central Vancouver Island. Now we are able to rely on a hypocenter profile and on a teleseismic receiver function profile [Audet et al., 2010] to provide improved constraints on slab depths to $40 \mathrm{~km}$. In this region the new model (Figure 5a) depicts somewhat steeper dips at slab depths above $35 \mathrm{~km}$ (yielding downward shift $<5 \mathrm{~km}$ ) and slightly less steep dips at slab depths below $35 \mathrm{~km}$ (yielding upward shift $<5 \mathrm{~km}$ ). Depth control remains sparse at the northern end of the subduction system.

[20] The arch in the slab beneath British Columbia and Washington covers the same general area as the previous model, but has a somewhat different shape (Figure 5a). Our new model depicts the shallower slab $(<40 \mathrm{~km}$ slab depth) with a less pronounced arch and the deeper slab with more complex shape based on dozens of new data points from active source, passive source, and hypocenter profiles.

[21] Slab contours beneath northern Oregon are little changed between models (Figure 5a) as little new data were available to refine slab geometry in this area. Likewise, shallow slab contours $(<30 \mathrm{~km})$ beneath southern Oregon are little changed. The deeper Oregon contours, while depicting somewhat less steep slab dips than our previous model, remain entirely interpolated between sparse depth control points.

[22] Shallow slab contours $(<40 \mathrm{~km})$ beneath northern California are substantially different from our previous model (Figure 5a) based on dozens of new control points from hypoDD profiles. Deeper contours are little changed from our previous model in this region as little new data were available to refine slab geometry. In sum, the new handcontoured slab model refines the slab shape in regions where substantial new data are available and indicates where interpolation occurs. Unlike the hand-contoured version, the computer-generated version does not truncate contours beyond where depth control is available. This version extrapolates continuous contours down to $90 \mathrm{~km}$ for ease of use in modeling studies.

\section{Sources of Uncertainty From Wadati-Benioff Zone Earthquakes}

\subsection{Network Velocity Models}

[23] We use hypocenter locations as the primary data source to infer the location of the top of the slab in those regions where seismicity is available. However, these hypocenter locations have uncertainties associated with them owing to uneven seismograph station coverage (Figure 2) and the one-dimensional (1D) velocity models used by regional networks to locate earthquakes. In particular, coastal and offshore events often have poor depth resolution (Figure 2) owing to the lack of offshore station control. In addition, the JdF slab mantle forms a dipping high velocity layer with respect to overlying crustal rocks whereas $1 \mathrm{D}$ velocity models inherently assume horizontal velocity changes. Thus, where the slab is shallow in the coastal and offshore areas, 1D velocity models can shift events somewhat deeper than their actual location [e.g., Taber and Smith, 1985] and conversely where the slab is deep such as under Puget Sound, these models can shift events shallower than their actual location [e.g., Creager et al., 2002]. Together, these two biases would tend to flatten apparent slab dip.

\footnotetext{
Figure 5. (a) Map comparing new hand-contoured model of depth to the Juan de Fuca slab surface denoted by blue lines to previous version [McCrory et al., 2006] denoted by thin black lines (see text for discussion; Figure 4a for explanation of the line styles for the new contours). For 2006 model, solid lines denote $10 \mathrm{~km}$ depth contours; dashed lines denote supplemental $5 \mathrm{~km}$ contours. Note that the new model depicts greater geometric complexity than previous one. (b) Map comparing new hand-contoured model of the Juan de Fuca slab surface to the version constructed by Audet et al. [2010] for depth contours of 20,30, and $40 \mathrm{~km}$. Blue lines denote our contours; thin black lines denote Audet et al. contours; inverted triangles denote control points for Audet et al. contours. Note the marked divergence between about $45^{\circ}$ and $49^{\circ} \mathrm{N}$, where the Audet et al. model is up to $10 \mathrm{~km}$ shallower than our model beneath the Olympic Peninsula and southernmost Vancouver Island. (c) Hypocenter profiles E05, F06, and F09 (with $60 \mathrm{~km}$ swath width) depicting location of the Audet et al. slab surface (see Figure $5 \mathrm{~b}$ for profile locations). Audet et al. slab surface denoted by dashed dark gray line; location of the slab crust based on hypocenter data (this study) denoted by thick light gray line; inverted brown triangle denotes location of trench axis; inverted blue triangle denotes location of coastline; inverted triangles denote depth control points for Audet et al. model (see Figure 3). ANSS hypocenters (1975-2009) colored by depth error (see Figure 2 for explanation). (See Figure 1 for base map notes.)
} 


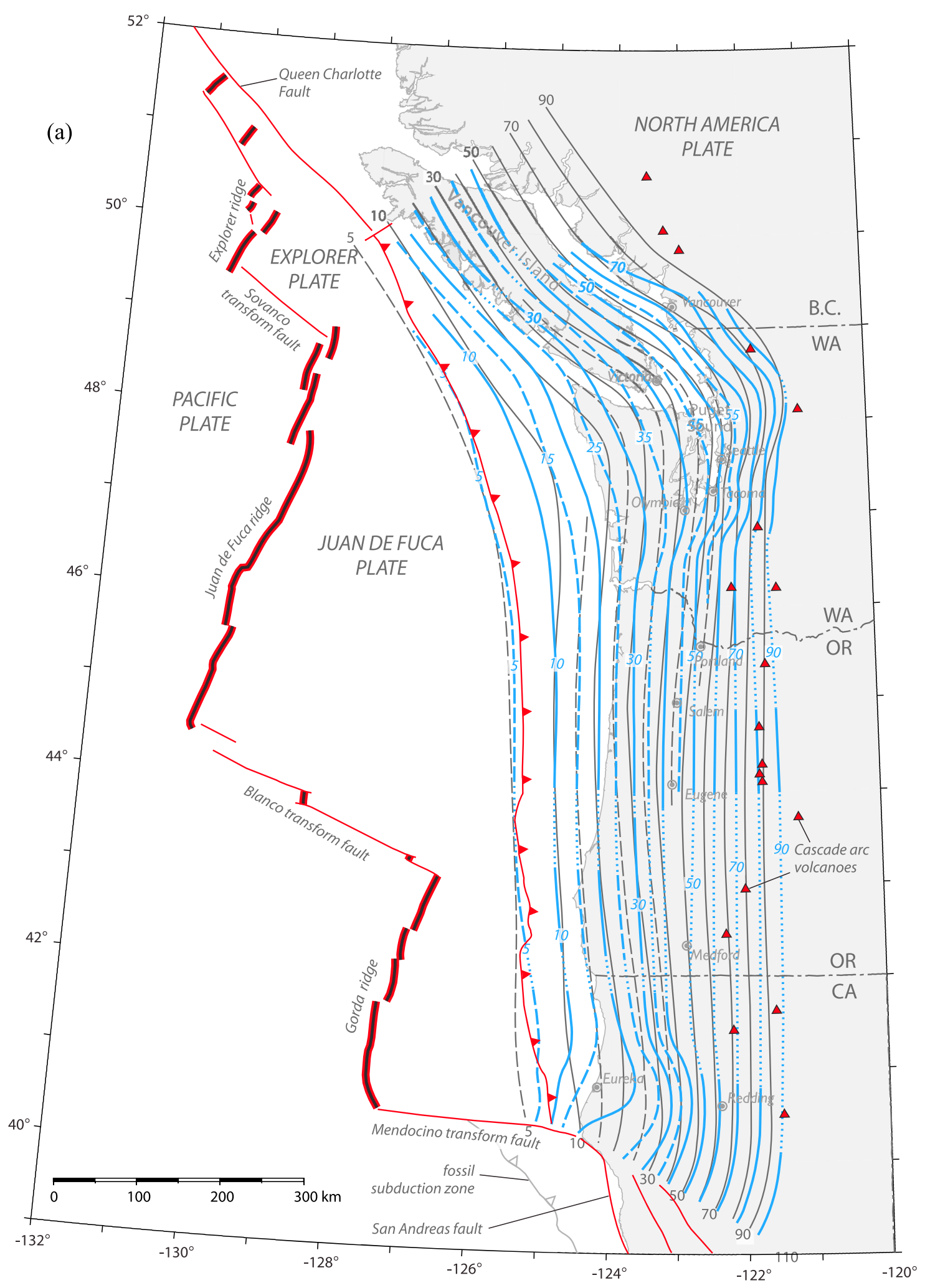

Figure 5 


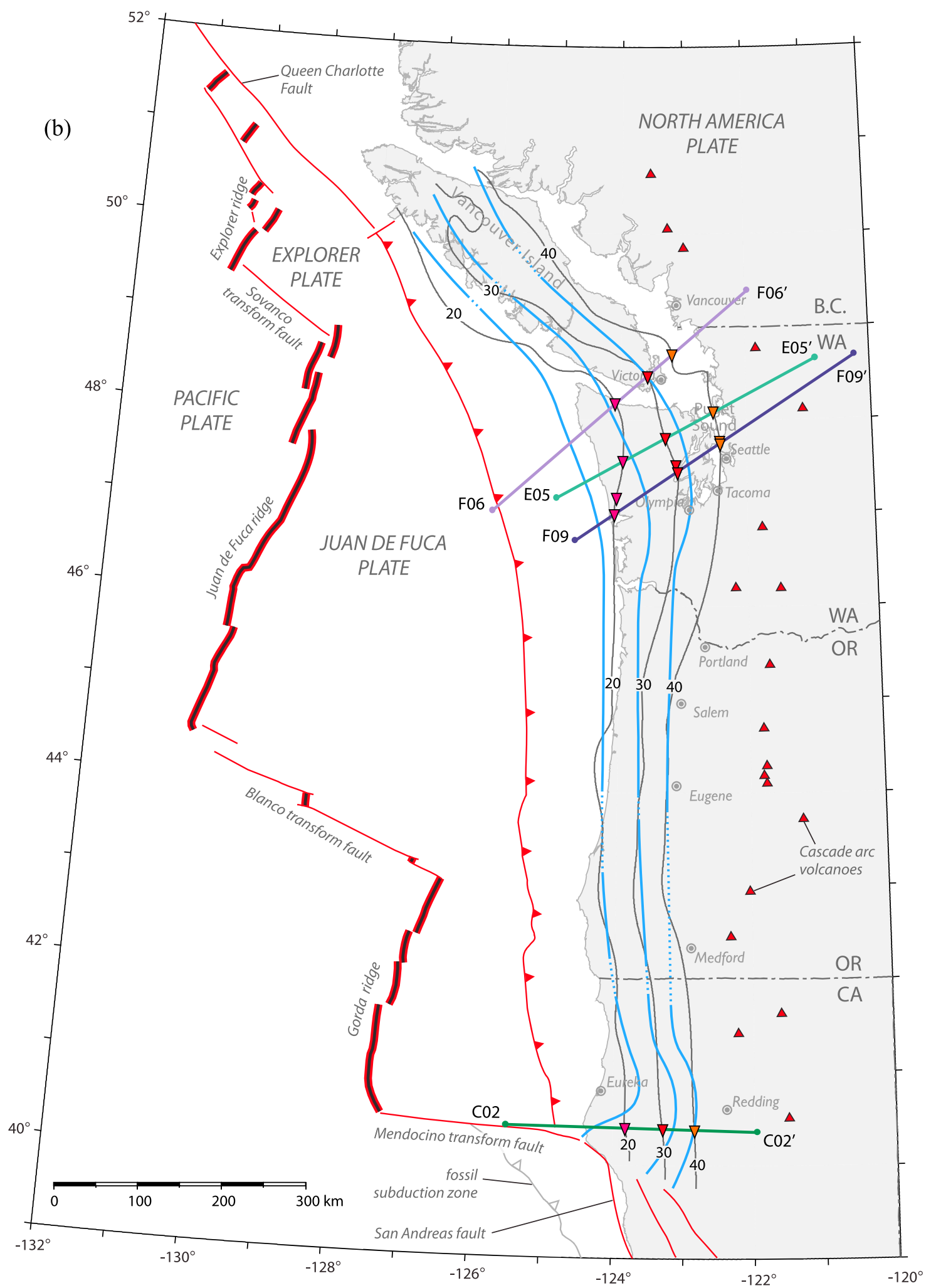

Figure 5. (continued) 
PROFILE E05-E05' $\cdot$ SW-NE transect starting at $47.15^{\circ} \mathrm{N} \& 125.0^{\circ} \mathrm{W}$ with an azimuth of $60^{\circ}$

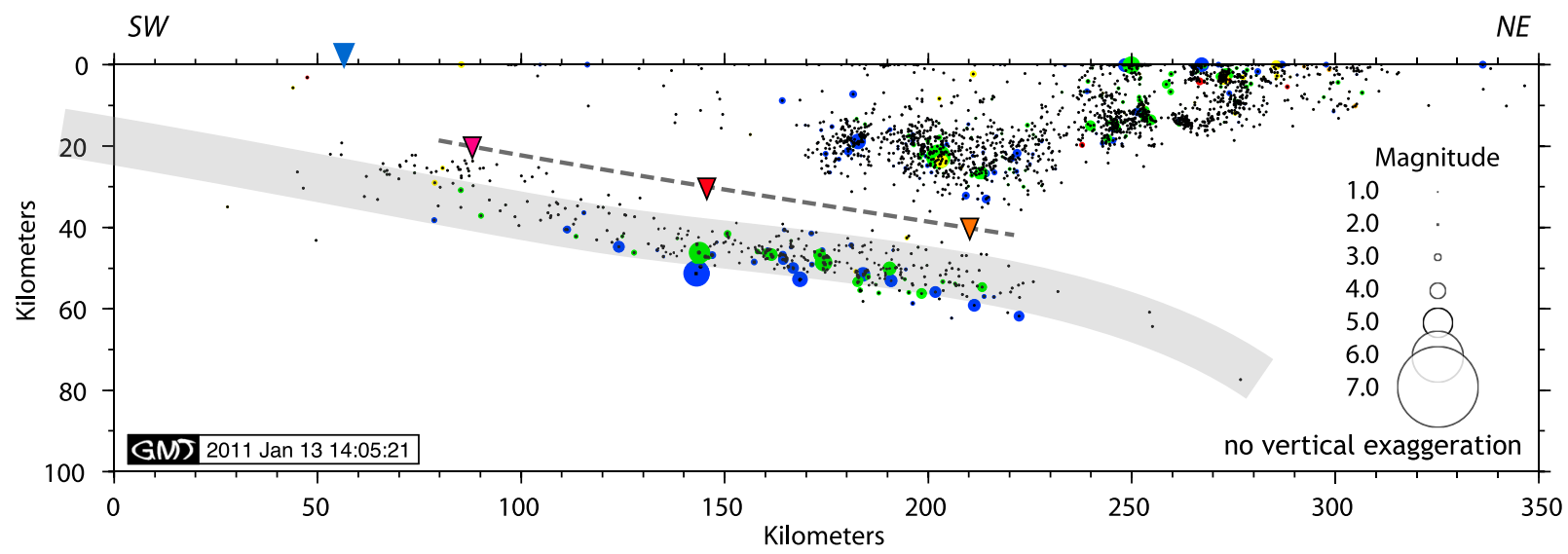

PROFILE F06-F06' $\cdot$ SW-NE transect starting at $47.0^{\circ} \mathrm{N} \& 126.0^{\circ} \mathrm{W}$ with an azimuth of $47^{\circ}$ (this profile supercedes a profile published in Weaver and Baker, 1988)

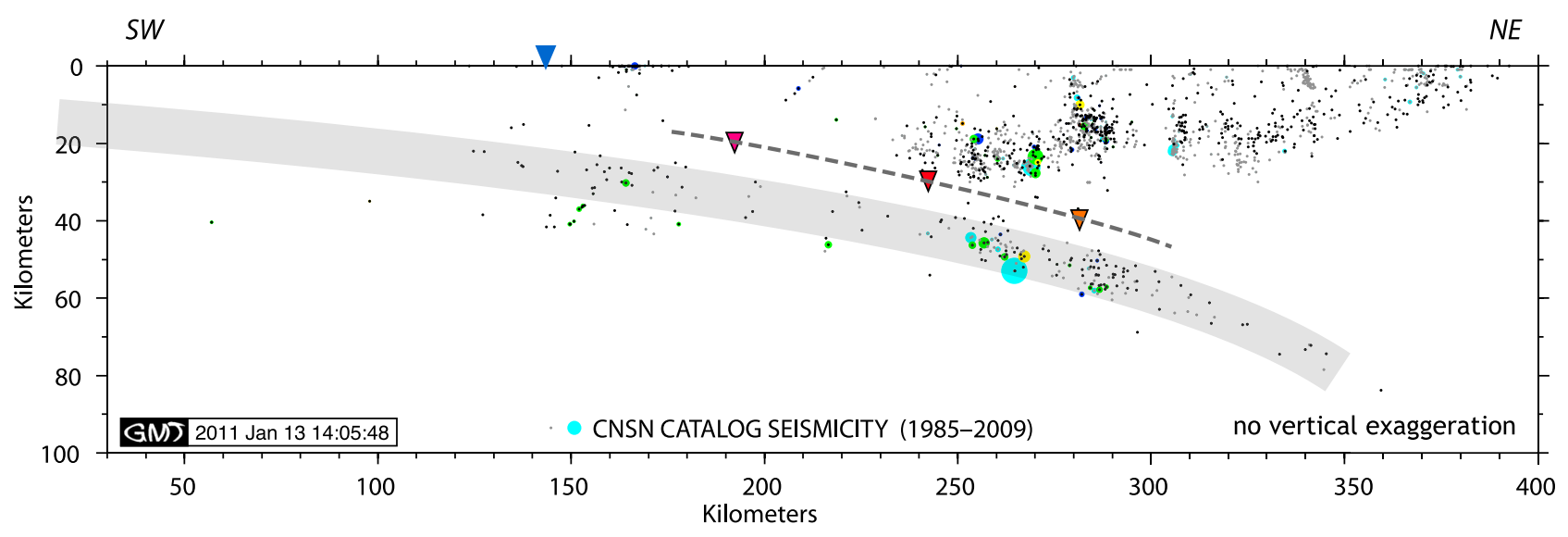

PROFILE F09-F09' $\cdot$ SW-NE transect starting at $46.7^{\circ} \mathrm{N} \& 124.7^{\circ} \mathrm{W}$ with an azimuth of $55^{\circ}$ (this profile supercedes profile $\mathrm{C} 02$ published in McCrory et al., 2004)

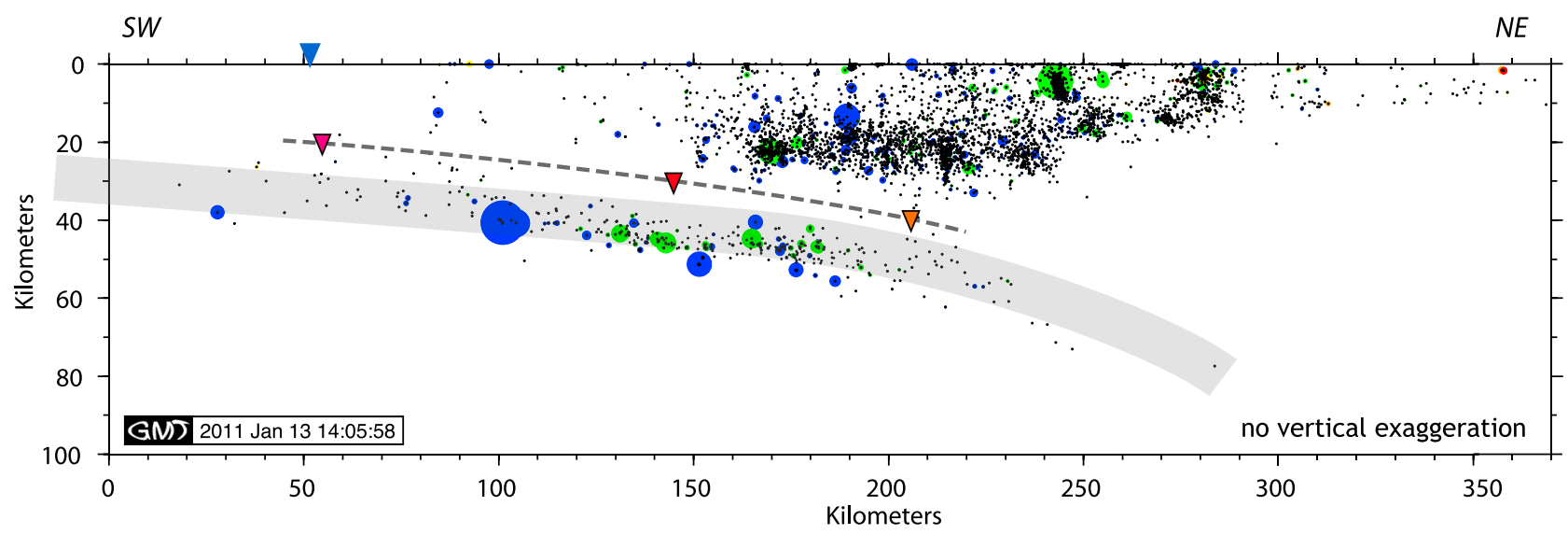

Figure 5. (continued) 
[24] The Cascadia forearc also has large lateral velocity contrasts associated with juxtaposition of deep sedimentary basins having relatively slow velocities (e.g., the Seattle basin) and accreted oceanic terranes having relatively fast velocities (e.g., the Siletz-Crescent terrane). For example, joint 3D seismic velocity studies and earthquakes relocations in the Vancouver Island-Puget Sound region result in vertical shifts in hypocenter locations up to $3 \mathrm{~km}$ and lateral shifts up to $1 \mathrm{~km}$ [e.g., Ramachandran et al., 2006]. To date no systematic relocation of PNSN or CNSN earthquakes, based on a comprehensive regional 3D velocity model, has been undertaken. Therefore, we use CNSN and PNSN catalog locations cognizant that individual hypocenter depth uncertainties may be up to $3 \mathrm{~km}$ larger than network error calculations indicate. Uncertainties offshore Oregon are likely even larger. Williams et al. [2011] relocated two seismicity clusters offshore central Oregon using the hypoDD method which shifted hypocenters up to $13 \mathrm{~km}$ shallower (with respect to ANSS locations). Their relative locations are much improved, yet the absolute locations may still have substantial uncertainties owing to the lack of permanent seismograph stations west of the clusters (see RMS plot in their Figure 5). The GeoPRISMS OBS deployment planned for this area should reduce location uncertainties when integrated with regional data.

[25] The NCSS catalog has been relocated (1984-2008) using the hypoDD method [Waldhauser and Schaff, 2008] (http://www.ldeo.columbia.edu/ felixw/NCAeqDD/ 200812), so relative locations in northern California are much improved, and we use these earthquake locations when mapping the location of the slab. Although systematic bias in the original NCSS starting locations is not specifically corrected for in the $D D$ catalog, absolute $D D$ locations can still be better than those of the corresponding network solutions. This is particularly true in areas with good station coverage, but less so in areas where complex velocity structure or sparse station coverage may introduce such bias.

\subsection{Rheological Models}

[26] Another source of uncertainty with respect to constraining the location of the slab stems from varying assumptions about where seismicity occurs within the slab. For the discussion below, we define WBZ seismicity as "shallow" if it occurs where the top of the slab is above $40 \mathrm{~km}$ depth, "intermediate" if it occurs where the top of the slab is between 40 and $60 \mathrm{~km}$ depth and "deep" if it occurs where the top is below $60 \mathrm{~km}$ depth. Some studies place shallow WBZ seismicity mainly in the uppermost mantle of the slab [e.g., Preston et al., 2003; Nedimović et al., 2003; Ramachandran et al., 2006], whereas others place shallow seismicity mainly within slab crust [e.g., Hyndman et al., 1990; Graindorge et al., 2003; Henstock and Levander, 2003]. Furthermore, some studies place intermediate seismicity within uppermost slab mantle [e.g., Parsons et al., 1999; Zhao et al., 2001], whereas others place WBZ intermediate seismicity in lower slab crust [e.g., Preston et al., 2003]. HypoDD relocated seismicity beneath eastern Vancouver Island depicts earthquakes within both upper crust and uppermost mantle at intermediate depths [Cassidy and Waldhauser, 2003].

[27] Rheological models [e.g., Kirby, 1995; Hacker et al., 2003a, 2003b] suggest that WBZ seismicity generally shifts from oceanic mantle to oceanic crust as a slab descends owing to both temperature- and pressure-dependent metamorphic reactions [e.g., Kirby, 1995; Peacock et al., 2002; Preston et al., 2003]. Specifically, mantle earthquakes correlate with antigorite or chlorite dehydration within hydrated mantle rocks when temperatures reach approximately $600^{\circ} \mathrm{C}$. In simple terms, mantle earthquakes are primarily attributed to geo-fluids released during dehydration as serpentinite (i.e., hydrated mantle rock) transforms back to peridotite [e.g., Hacker et al., 2003b]. This metamorphic reaction increases pore pressure which reduces effective normal stress [e.g., Scholz, 1998] and, thereby, promotes brittle reactivation of pre-existing faults [e.g., Kirby et al., 1996; Peacock et al., 2002; Hacker et al., 2003b].

[28] Crustal earthquakes are primarily attributed to a similar process, but in their case, geo-fluids are released during dehydration and densification of basalt and gabbro when they transform to eclogite. The densification and transformation of basalt or gabbro to eclogite occurs at pressures of 1.3 $2.0 \mathrm{GPa}$ in the Cascadia subduction system, corresponding to depths of 40-60 km [Peacock et al., 2002; Hacker et al., 2003b]. Thermal models of the Cascadia subduction system that include the cooling effects of hydrothermal circulation within JdF crust [Cozzens, 2011] suggest that eclogite transformation begins at slab depths of $40-45 \mathrm{~km}$, corresponding to pressures of $1.25-1.35 \mathrm{GPa}$ (and a temperature of $\sim 510^{\circ} \mathrm{C}$ ) similar to simpler thermal models.

[29] If these rheological models are correct, then where only a single zone of WBZ seismicity can be discerned in Cascadia, the zone may depict a somewhat flatter slab dip than actually exists as hypocenters shift from oceanic mantle to oceanic crust with depth. Moreover, if there are areas where slab seismicity occurs mainly in the mantle, but has been incorrectly assumed to be concentrated in the crust, the actual slab surface could be as much as $5 \mathrm{~km}$ shallower. Conversely, if there are regions where slab seismicity occurs mainly in the crust, yet has been incorrectly assumed to be concentrated in the upper mantle, the actual slab surface could be as much as $5 \mathrm{~km}$ deeper.

[30] Although mantle and crustal dehydration processes are both driven by changes in temperature and pressure as well as fluid content, they occur somewhat independently. Under some rheological regimes the dehydration fields overlap, resulting in mantle and crustal earthquakes occurring at similar slab depths, yielding double seismic zones (DSZ). The Hacker et al. model [2003b] predicts that in slabs with stacked layers of seismicity, the upper seismic zone shifts downward from upper to lower crust (i.e., from basalt to gabbro) as the slab descends. The lower seismic zone shifts upward from uppermost mantle toward the Moho with increasing slab depth. Such shifts result in the two zones pinching together and converging on the Moho with depth. If this model is accurate, DSZ seismicity may resolve a somewhat steeper apparent slab dip if the upper layer were assumed to define the plate interface, but in fact shifted downward from upper to lower crust with depth.

[31] Beneath Vancouver Island, Cassidy and Waldhauser [2003] found that WBZ earthquakes delineated a DSZ at intermediate slab depths. Through a combination of $P$ and $S$ wave velocity models, seismic reflection profiles, and hypoDD relocations of earthquakes in the CNSN catalog, their study constrained the upper seismic zone to upper crust 
and the lower zone to uppermost mantle separated by an aseismic layer about $5 \mathrm{~km}$ thick, inferring a slab thickness of 6-7 km. Narrow aseismic layers separating seismic zones have been observed elsewhere, such as in the Nazca plate, where the upper seismic zone also occurs in upper crust and the lower zone occurs in uppermost mantle [Rietbrock and Waldhauser, 2004]. In addition, both studies observed that the largest magnitude WBZ earthquakes occurred just beneath the Moho. Where a DSZ can be mapped below northern California, we use the Vancouver Island observations to constrain the location of the slab.

\subsection{Scheme for Handling Discrepancies Between Data Sets}

[32] The DSZ beneath northern California, first detected by Smith et al. [1993], is key to our efforts to constrain the depth of the JdF slab. Wang and Rogers [1994] attributed the upper seismic zone to brittle fracture of upper crust and the lower seismic zone to brittle fracture of uppermost mantle, separated by a layer of aseismic ductile lower crust. We interpret the narrow aseismic layer beneath northern California as spanning the lower crust and Moho, and infer the JdF slab surface (top of Layer 2) to be approximately 6-7 km above the Moho [Clowes et al., 1987; Cassidy and Waldhauser, 2003; Nedimović et al., 2005].

[33] The hypoDD relocations of NCSS catalog earthquakes allow us to map the full extent of the DSZ (Figure 6a) beneath northern California. In particular, these hypocenters delineate a shallow DSZ from about 15 to $30 \mathrm{~km}$ depth (corresponding to a slab top from $\sim 10-25 \mathrm{~km}$ depth), separated by a narrow aseismic layer. Since the relative uncertainties of these relocations are a few hundred meters or less, the approximately $4 \mathrm{~km}$ thick aseismic layer should be resolvable, allowing us to discriminate between a double and a single zone of seismicity. The two seismic zones beneath northern California appear to merge downward into single zone that spans the entire crustal thickness (Figure 6a), although depth uncertainties associated with deeper hypocenters do not allow us to confirm this. This apparent single zone of seismicity extends to a depth of about $45 \mathrm{~km}$ (Figures $4 \mathrm{a}$ and $6 \mathrm{a}$ ).

[34] These hypocenter patterns are consistent with observations of seismicity beneath the Tokai region of southwestern Japan, where a DSZ in the young Philippine Sea plate $(<25$ Ma [Müller et al., 2008; Lin, 2011]) can be resolved from about 30 to $45 \mathrm{~km}$ depth (corresponding to a slab top from $\sim 20-35 \mathrm{~km}$ depth), separated by an aseismic layer about $7 \mathrm{~km}$ thick [Matsubara et al., 2008]. In contrast, the seismic zones that make up the DSZ in the colder, thicker Pacific plate beneath northeastern Japan (>120 Ma [Müller et al., 2008]), found between depths of 50 to $140 \mathrm{~km}$, are separated by an approximately $40 \mathrm{~km}$ thick aseismic layer [Hasegawa et al., 1994; Igarashi et al., 2001], which is not particularly useful for constraining the location of the Moho.

[35] JdF seismicity is often too sparse or poorly located for us to resolve a posteriori whether it occurs in slab mantle or crust. In such regions, we extrapolate NCSS hypoDD observations. We assume that the bulk of the seismicity within the shallower updip portion of the slab occurs in uppermost mantle rocks and is associated with temperaturedependent serpentinite dehydration [e.g., Peacock et al., 2002; Hacker et al., 2003b; Preston et al., 2003]. We assume the largest magnitude WBZ earthquakes occur in uppermost mantle, since it represents the strongest element within oceanic lithosphere [Cassidy and Waldhauser, 2003]. With sparse network coverage near the coast, the locations of these larger events are likely to be better resolved than the smaller events which sometimes appear as scattered hypocenters above the mapped slab surface (e.g., Figure S3; profile E05, E06 or E08 in the auxiliary material). Our goal is to provide the most accurate model possible, rather than distort the slab surface to capture relatively poorly located microseismicity. This approach results in a few small events that are likely WBZ earthquakes, falling above the mapped slab surface. We capture these smaller events in our WBZ earthquake catalog by employing a $2.5 \mathrm{~km}$ high envelope above the slab surface in $A r c G I S$ when separating earthquakes that occur above or below the hand-contoured surface.

\section{Sources of Uncertainty From Seismic Velocity Models}

\subsection{Velocity Uncertainties}

[36] Discrepancies in JdF slab depths derived from available seismic velocity models are minimal beneath Oregon and northern California. Beneath Vancouver Island and Washington, depths derived from various active source models are generally consistent, but can differ up to $5 \mathrm{~km}$ in a few locations. As described above, we address these discrepancies through a weighting scheme on the basis of the comprehensiveness of the modeling effort.

[37] Between depths of 20-40 km beneath Washington and Vancouver Island, a slab model based primarily on passive source, converted $S$ wave phases [Audet et al., 2010] depicts $\mathrm{JdF}$ crust up to $10 \mathrm{~km}$ shallower than models based on active source, $P$ wave velocities (Figures $5 \mathrm{~b}$ and $5 \mathrm{c}$ ). This discrepancy may simply stem from $P$ wave and $S$ wave data resolving different aspects of the same seismic velocity structure.

[38] The location of the slab inferred from teleseismic receiver function data [e.g., Audet et al., 2010] is based on a LVZ with the approximate thickness of oceanic crust and the approximate velocity of hydrated oceanic crust [e.g., Hyndman, 1988], and placing the slab surface along the top of the LVZ. Whereas, the location of the slab inferred from wide-angle refraction data is based on mapping a sharp $P$ wave velocity gradient as the oceanic Moho, and placing the slab surface 6-7 km above this boundary [e.g., Preston et al., 2003]. Similarly, the location inferred from MCS reflection data is based on mapping the Moho reflection approximately at the base of a thick reflection package as the oceanic Moho and, again, placing the slab surface 6-7 km above this reflector [e.g., Nedimović et al., 2003]. Audet et al. [2010] attribute the deeper slab location in $P$ wave models to those models not accounting for $20 \%$ lower than expected velocities in and below a LVZ. With the passive and active source studies relying on different data sets, and employing different parameters and modeling schemes, the $\leq 10 \mathrm{~km}$ variability may simply reflect model uncertainties as Audet et al. [2010] suggest.

\subsection{Structural Uncertainties}

[39] Alternatively, the passive and active studies may be identifying different tectonic elements thereby labeling entirely different structures as the JdF slab. In particular, the 
PROFILE C02-C02' (supercedes McCrory et al., 2006, line A1) - W-E transect starting at $40.4^{\circ} \mathrm{N} \& 125.5^{\circ} \mathrm{W}$
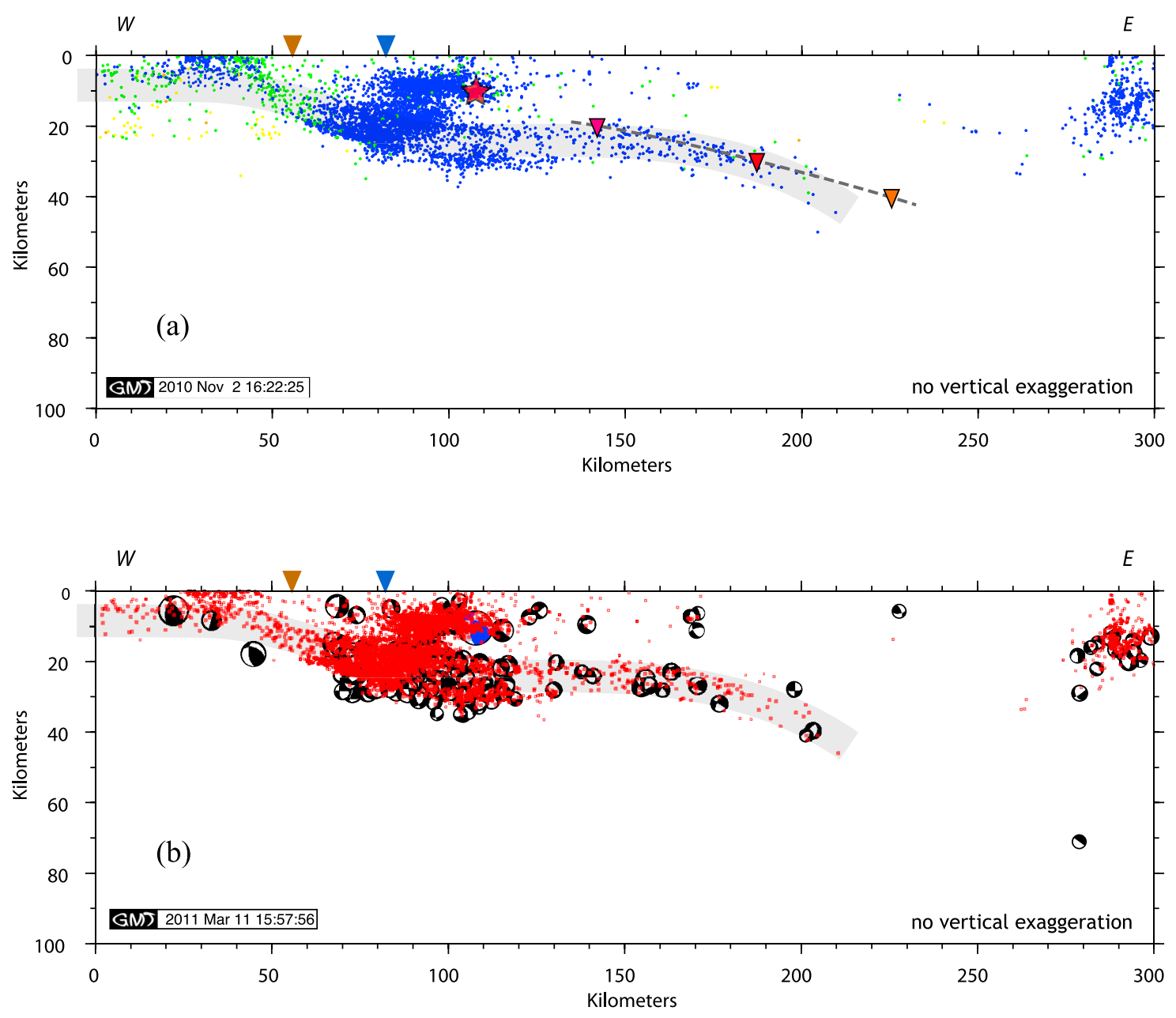

Figure 6. (a) Profile showing double seismic zones (DSZ) beneath northern California based on NCSS hypoDD hypocenter locations (1984-2008; http://www.ldeo.columbia.edu/ felixw/NCAeqDD/200812). A $20 \mathrm{~km}$ wide swath is projected onto the plane of the $\mathrm{C} 02$ profile line (see Figure $5 \mathrm{~b}$ for profile location). See Figure $5 \mathrm{c}$ for an explanation of the symbols. The DSZ extends about $90 \mathrm{~km}$ east from trench axis. Note the seismicity cluster about $10 \mathrm{~km}$ above the modeled slab surface. This cluster includes the main 1992 M7.1 shock and associated aftershocks (see text for discussion). Main shock denoted by red star. Hypocenters colored by depth error. This profile is in the same location as the Oppenheimer et al. [1993, Figure 2a] profile, but the swath width of their profile was $40 \mathrm{~km}$. (See auxiliary material for additional profiles.) (b) Profile showing first-motion mechanisms with magnitude $>2.5$ (1975-2009; from Northern California Earthquake Data Center (NCEDC) mechanism catalog) within $10 \mathrm{~km}$ of the C02 profile line. Main shock denoted by mechanism with blue compressional quadrants. HypoDD seismicity (1984-2008; http://www.ldeo.columbia.edu/ felixw/NCAeqDD/200812) is denoted by open red circles. Note that this profile is oblique to the direction of fault rupture.

presence of a detached fragment of Eocene oceanic lithosphere in the Vancouver Island-Washington forearc [McCrory and Wilson, 2010; Wilson and McCrory, 2010] complicates correlations between seismic velocity structures and tectonic elements. Many regional studies distinguish two stacked dipping units (i.e., the so-called E- and F- layers of Hyndman et al. [1990] and Cassidy and Waldhauser [2003]) with oceanic crustal velocities beneath southern Vancouver Island and the Strait of Juan de Fuca. These studies correlate the deeper F-layer with the JdF crust and the shallower E-layer with either a stranded fragment of oceanic crust or a wide shear zone located at the top of the subducting oceanic crust. Audet et al. [2010] only resolve the shallower E-layer, and thus correlate this layer with JdF crust. We need to consider whether the depth discrepancies may simply reflect the depths of different tectonic elements.

[40] The LVZ beneath western Washington may not be restricted to hydrated oceanic crust. Calvert et al. [2011] suggest that the LVZ here likely represents hydrated lower continental crust at the base of the overlying forearc because the LVZ diverges significantly from the slab Moho with depth, inconsistent with an interpretation that it represents oceanic crust. Calvert et al. [2011] attribute the LVZ to fluidsaturated sedimentary rocks scraped from the top of the 
subducting slab. Calkins et al. [2011] attribute the LVZ to hydrated lower continental crust as well, but postulate that the lower crust may be hydrated by fluids released from the JdF slab.

[41] Finally, the shallower slab depicted in the Audet et al. [2010] model implies that WBZ seismicity observed beneath southern Vancouver Island and Washington is occurring in oceanic mantle several kilometers below the Moho and that none is occurring in oceanic crust (Figure $5 \mathrm{c}$ ). Such a pattern would conflict with well-studied subduction zones such as Nankai where WBZ seismicity occurs close to the oceanic Moho in both $P$ wave and $S$ wave models [e.g., Hirose et al., 2008]. Similarly, a Washington slab location based on $P$ wave models places WBZ seismicity in close proximity to the Moho (Figure 5c) consistent with Nankai. Beneath northern California, where the Audet et al. model and ours depict similar slab depths (Figures $5 \mathrm{~b}$ and $6 \mathrm{a}$ ), and where slab depth is well constrained by double seismic zones, WBZ seismicity is also concentrated near the Moho.

\subsection{Scheme for Handling Discrepancies Between Data Sets}

[42] Questions about whether the Audet et al. [2010] model maps JdF crust beneath Vancouver Island and Washington or instead maps overlying Eocene oceanic crust [McCrory and Wilson, 2010; Wilson and McCrory, 2010] and underplated material, respectively, precludes our using their depth constraints where large discrepancies occur. We do utilize depth constraints derived from Audet et al. [2010] profiles across northern Vancouver Island where few depth constraints are available and the possibility of subsurface oceanic fragments is unlikely.

[43] Examination of the basis for these discrepancies is critical to quantifying uncertainties and improving the accuracy of slab models by determining whether or not these differences reflect different assigned parameters, different data sets, different modeling schemes, or different tectonic elements. This issue could be investigated by development of integrated $V p, V s$, and $V p / V s$ models for the Cascadia subduction margin similar to those available for the Nankai subduction system beneath southwestern Japan [e.g., Hirose et al., 2008; Matsubara et al., 2008, 2009; Uchida et al., 2009] and the Hikurangi subduction zone beneath New Zealand [Reyners and Eberhart-Phillips, 2009]. For Nankai and Hikurangi, comprehensive seismic velocity and attenuation $(Q p)$ models yield no such discrepancies in slab depths.

\section{Observed Slab and Forearc Earthquake Patterns}

[44] Most WBZ earthquakes beneath British Columbia occur offshore the west coast of Vancouver Island from 50 to $48^{\circ} \mathrm{N}$. These earthquakes track a shallow section of slab where its depth ranges from 15 to $30 \mathrm{~km}$ (Figure 4a). Forearc earthquakes occur as isolated clusters above the WBZ where slab depths range from 10 to $30 \mathrm{~km}$. Some forearc clusters form linear trends that may illuminate faults such as the NW-SE trending cluster that crosses the Washington coastline near Makah Bay (Figure 4b). This particular cluster may illuminate an offshore extension of the Calawah fault although it overlies a similar trend in slab earthquakes, suggesting a more complicated tectonic setting.
[45] WBZ earthquake locations shift abruptly from shallow to intermediate depths between Vancouver Island and Washington. From the Strait of Georgia to the south end of Puget Sound, $\left(49-47^{\circ} \mathrm{N}\right)$, most WBZ earthquakes occur at slab depths ranging from 30 to $50 \mathrm{~km}$. Interestingly, models of geodetic coupling along the Cascadia subduction fault depict a sharp increase in coupling [McCaffrey, 2009] where the WBZ shifts from shallow to intermediate depths, perhaps indicating a change in rheology along the subduction boundary.

[46] The shift in location of forearc earthquakes is less abrupt. Nonetheless, forearc epicenters outline a fairly sharp western edge, situated above the $40 \mathrm{~km}$ slab contour (Figure $4 \mathrm{~b}$ ), and continue eastward to the edge of our slab model at the Cascade Arc. WBZ and forearc epicenters overlap between slab depths of 40-50 km. The WBZ earthquakes also occur within the updip portion of the slab, while forearc earthquakes overlie downdip portions of the slab. Clustered forearc events in western Washington have been previously correlated with arc-related shear zones and mapped crustal faults.

[47] WBZ earthquakes are almost nonexistent from about $47^{\circ} \mathrm{N}$ south to the Oregon border at $42^{\circ} \mathrm{N}$. Two small clusters occur at shallow slab depths $(15-20 \mathrm{~km})$ offshore central Oregon. These clusters may not be slab events as relocations by Williams et al. [2011] shift them upward to the slab interface and accretionary prism. A band of forearc epicenters occur from $47^{\circ} \mathrm{N}$ south to $45^{\circ} \mathrm{N}$. These earthquakes occur above slab depths of $45-70 \mathrm{~km}$ and are primarily attributed to arc-related shear zones and mapped crustal faults. The distribution of earthquakes in Oregon yields no spatial correlations between slab and forearc epicenters.

[48] An abrupt shift from almost no earthquakes to abundant shallow WBZ earthquakes begins at about $42^{\circ} \mathrm{N}$ and continues south to $40^{\circ} \mathrm{N}$. These earthquakes occur at slab depths ranging from 5 to $35 \mathrm{~km}$. Interestingly, there is a sharp cutoff to WBZ earthquakes, approximately $30-40 \mathrm{~km}$ north of the slab edge (Figure 4a). Forearc earthquakes occur from 42 to $39^{\circ} \mathrm{N}$ and overlie the entire width of our slab model. However, they are noticeably less abundant where slab depths range from 25 to $50 \mathrm{~km}$. Forearc earthquakes are most prevalent from the trench east to where the slab reaches a depth of about $22 \mathrm{~km}$, suggesting a link between processes that promote slab and forearc events in this area. A few forearc clusters above the south end of the slab (Figure 4b) likely illuminate nascent northern extensions of San Andreas fault traces.

\section{Relationship Between Slab Geometry and Earthquake Occurrence}

[49] The release of geo-fluids during metamorphism of the subducting oceanic plate can promote earthquake occurrence within the slab by increasing pore pressure, thereby reducing effective normal stress so as to enable unstable (stick-slip) frictional sliding in material that would otherwise flow in a stable sliding manner [e.g., Kirby, 1995; Scholz, 1998]. However, the lack of a continuous band of WBZ epicenters along the Cascadia subduction system suggests that typical metamorphic processes are not sufficient to trigger earthquakes in inferred brittle layers within the JdF slab. 
[50] Our slab model can be used to investigate whether additional stress from plate flexure associated with warping may promote WBZ earthquake occurrence [cf. Choy and Kirby, 2004]. For example, the distribution of slab epicenters indicates that WBZ seismicity occurs mainly beneath northern California and western Washington where the slab appears to be warped or buckled (Figure 4a). Conversely, where slab dip appears to smoothly increase with depth beneath Oregon, few WBZ earthquakes have been recorded. The earthquake clusters offshore central Oregon are attributed to an additional stressor [Williams et al., 2011], namely seamount relief on the plate surface, consistent with the hypothesis that geometric complexity promotes the occurrence of small earthquakes.

\subsection{Western Vancouver Island}

[51] A distinct band of shallow WBZ epicenters occurs along the west side of Vancouver Island, north of $48^{\circ} \mathrm{N}$. This section of slab does not appear to be warped, ruling out slab flexure as a primary factor promoting earthquake occurrence. Available thermal models suggest that conditions conducive to upper mantle earthquake occurrence begin at a slab depth of about $22 \mathrm{~km}$, consistent with observations. Although offshore locations are not well constrained, this northern band of earthquakes occurs at the depth range predicted for upper mantle events in the slab. Shallow WBZ earthquakes in this band are most prevalent near the Nootka fracture zone (Figure 4a) where focal mechanisms indicate E-W tension associated with shear along the fracture zone [Wada et al., 2010]. Although we lack well resolved slab geometry in this region, this earthquake pattern suggests that internal deformation of the JdF plate near the fracture zone promotes earthquake occurrence. Crustal slab earthquakes are most abundant between slab depths of 20-30 km (see Figure S3; profiles E08, F01, and F02 in the auxiliary material), too shallow for a basalt-to-eclogite transformation driven primarily by increased pressure.

\subsection{Western Washington}

[52] The slab beneath western Washington forms a fairly broad arch, extending about $250 \mathrm{~km}$ along strike and $250 \mathrm{~km}$ downdip, with a somewhat sharp kink bounding the south side. WBZ earthquakes are concentrated between slab depths of 30-50 km (Figure 4a), with upper mantle earthquakes generally extending farther updip than crustal earthquakes [Preston et al., 2003] consistent with thermal models for Cascadia [Peacock et al., 2002; Hacker et al., 2003b; Cozzens, 2011]. The largest WBZ earthquakes, including the 2001 M6.8 Nisqually earthquake, are restricted to the southern edge of the arch, suggesting that stress (and strain) may concentrate along the slab kink [McCrory et al., 2003]. Earthquakes along the kink reach depths of more than $80 \mathrm{~km}$, by far the deepest earthquakes observed within the JdF slab, suggesting as well that this structure promotes brittle behavior to greater depth. Thus, the arched slab geometry beneath western Washington is associated with an expected WBZ seismicity pattern, except for the kink which seems to concentrate stress, thereby promoting recurring, larger magnitude events.

[53] Forearc earthquakes are most prevalent above the slab arch ( $>40 \mathrm{~km}$ slab depth; Figure $4 \mathrm{~b})$. Earthquake focal mechanisms indicate that forearc events are primarily responding to N-S-directed contraction within the forearc [Ma et al., 1996; Cassidy et al., 2000] rather than stresses directly attributable to slab geometry.

\subsection{Northern California}

[54] The slab beneath northern California contains a warped section which extends northward about $150 \mathrm{~km}$ along strike from the Mendocino triple junction and about $130 \mathrm{~km}$ downdip (Figure 4a). The slab is concave-down from the trench to approximately $20 \mathrm{~km}$ depth. Then its curvature reverses to become concave-up between 20 to $25 \mathrm{~km}$ depth, before reversing again to become concave downward below $25 \mathrm{~km}$ depth (Figure 6a). WBZ earthquakes are concentrated in this warped section between the trench and a slab depth of $30 \mathrm{~km}$.

[55] No thermal model is available for this portion of the Cascadia subduction zone. If we apply thermal models for Vancouver Island [Hacker et al., 2003b; Cozzens, 2011] as analogs based on similar age of the subducting plate, these models indicate that mantle dehydration should begin to occur at slab depths around $20-25 \mathrm{~km}$, somewhat deeper than what we observe.

[56] Shallower than predicted slab seismicity likely results from N-S compression between the Pacific and Juan de Fuca plates [Wilson, 1989, 2002] continuing across a subsurface extension of the Mendocino fracture zone as far east as the San Andreas fault system. Wang and Rogers [1994] and Wada et al. [2010] attribute WBZ strike-slip focal mechanisms between 15 and $25 \mathrm{~km}$ depth (Figure 6b) to such subsurface N-S compression. Similar internal plate deformation is observed adjacent to the Pacific- North America (Okhotsk)-Philippine triple junction, where the subducting Philippine Sea plate produces strike-slip earthquakes at shallow depths [Choy and Kirby, 2004]. The cutoff of WBZ seismicity, 30-40 km north of the mapped edge of the JdF slab, suggests that a fragment has broken from the southernmost $\mathrm{JdF}$ plate in this region of direct plate interaction (bounded by the westernmost and easternmost traces of the San Andreas fault system). Slab dip steepens below the region of direct plate interaction, conforming to slab dips to the north (Figure 4a). Focal mechanisms within the deeper slab indicate downdip extension (Figure 6b), commonly attributed to slab-pull forces [e.g., Spence, 1987].

[57] Available thermal models may explain much of the distribution of WBZ earthquakes beneath Vancouver Island and Washington. Slab flexure may be a factor in promoting WBZ and forearc earthquakes beneath northern California as well as the larger magnitude earthquakes beneath western Washington. However, slab geometry does not explain the lack of earthquakes beneath Oregon. Oregon remains an anomaly.

\section{Relationship Between Subduction Zone Fluids and Earthquake Occurrence}

[58] Several factors besides slab geometry can promote or suppress earthquake occurrence in a subduction setting, in particular, the hydration state of the oceanic plate along with the permeability of overlying forearc rocks [e.g., Hasegawa et al., 2007; Reyners and Eberhart-Phillips, 2009]. If WBZ 
earthquakes mark the location of high pore pressures associated with mantle and crustal dehydration, we can use them as a proxy for trench-parallel variability in slab rheology. If forearc permeability affects pathways of geo-fluids released during metamorphosis of the subducting slab, then its variability may perturb WBZ and forearc seismicity patterns.

\subsection{Role of Fluids}

[59] The hydration of the JdF plate appears to vary significantly along the Cascadia subduction margin. Internally deformed portions of the $\mathrm{JdF}$ plate may be unusually hydrated. In highly fractured regions of the oceanic plate seaward of the outer rise such as within the Gorda deformation zone (GDZ) and along pseudo-faults, the fractures serve as conduits for seawater to percolate downward and thereby alter crustal and upper mantle rocks well before they reach the outer rise where such fracture hydration typically occurs [Nedimović et al., 2009]. The subducted GDZ hosts abundant earthquakes in both the upper mantle and crust consistent with an interpretation of a hydrated slab undergoing metamorphic dehydration, albeit at unusually shallow depths.

[60] Thermal models across central [Bostock et al., 2002] and southernmost Oregon [Peacock et al., 2002] suggest that the uppermost mantle of the JdF plate reaches dehydration temperatures $\left(\sim 600^{\circ} \mathrm{C}\right)$ for serpentinized mantle seaward of the trench. If these thermal models are correct, they suggest that earthquakes are not expected to occur within anhydrous slab mantle beneath Oregon. Interestingly, the Cozzens [2011] thermal model for Oregon, calibrated with the Bostock et al. [2002] $S$ wave profile, does not require hydrothermal circulation within the crust consistent with an interpretation of an anhydrous slab.

[61] Shallow WBZ seismicity occurs near the coast of Vancouver Island $\left(50-48^{\circ} \mathrm{N}\right.$; Figure $\left.4 \mathrm{a}\right)$ in a portion of the JdF slab similar in age to the slab beneath northern California. A thermal model across southern Vancouver Island [Hacker et al., 2003b] suggests that the uppermost mantle of this very young oceanic plate reaches $600^{\circ} \mathrm{C}$ when the slab reaches a depth of approximately $22 \mathrm{~km}$, consistent with the location of mantle earthquakes. The Cozzens [2011] thermal model for Vancouver Island predicts hydrated, low permeability slab crust. Crustal earthquakes are most prevalent where the slab ranges from 20 to $30 \mathrm{~km}$ deep (see Figure S3; profiles $\mathrm{E} 08$, F01, and F02 in the auxiliary material) implying that crustal dehydration occurs somewhat shallower in younger (warmer) oceanic crust. Interestingly, two clusters of forearc epicenters occur above pseudo-faults in the Juan de Fuca slab [Wilson, 2002] where the plate is considered highly fractured and likely to be more hydrated than adjacent more intact areas [Nedimović et al., 2009], suggesting that fluids released from pseudo-faults may migrate into the accretionary prism.

[62] The Cozzens [2011] thermal model across Washington suggests that hydrated, low permeability JdF crust reaches eclogite transformation conditions at approximately $40 \mathrm{~km}$ depth (corresponding to a pressure of about $1.25 \mathrm{GPa}$ ). Larger magnitude earthquakes begin to occur near the Moho at about this depth (Figure S3; see profiles E04, E05, F03, or F04 in the auxiliary material), consistent with the Cozzens model. No thermal model is available for slab mantle conditions beneath Washington.

\subsection{Role of the Low Velocity Zone}

[63] High pore pressures in subsurface regions are often inferred from low seismic velocities, high $V p / V s$ values, and low $Q p$ values [e.g., Reyners and Eberhart-Phillips, 2009; Matsubara et al., 2009]. For Cascadia, Audet et al. [2010] attribute high $V p / V s$ values and low seismic velocities to high fluid pressures within oceanic crust. Audet et al. [2010] map a shallow LVZ beneath the entire Cascadia subduction margin, but we question whether the zone everywhere represents JdF crust. As discussed above, the LVZ may represent a detached fragment of Eocene oceanic crust beneath Vancouver Island and the Strait of Juan de Fuca, or represent hydrated lower forearc material beneath Puget Sound [Calvert et al., 2011; Calkins et al., 2011]. Although the JdF crust beneath Oregon may lack fluid-filled pores and fractures [Cozzens, 2011] and the upper mantle may enter the trench in an anhydrous state, the LVZ beneath Oregon could still represent oceanic crust if fractures are filled with geofluids released during the transformation of basalt and gabbro to eclogite. Evidence of a reflective zone beneath Oregon [Keach et al., 1989; Tréhu et al., 1994], with similar character to the E-layer beneath Vancouver Island, complicates this interpretation. The Oregon reflective zone raises the question of whether the LVZ beneath Oregon might instead represent hydrated rocks above the JdF plate trapped at the base of the overlying Siletz forearc terrane.

[64] Uchida et al. [2009] have examined the effect of upper plate seismic velocity structure on seismicity patterns along the Japan trench in northeastern Japan. The North American plate comprises the upper plate at the southern end of the Japan trench. Here, the Philippine Sea plate is situated between the North American (Okhotsk) plate and the subducting Pacific plate at depths $>50 \mathrm{~km}$. Relatively few WBZ earthquakes occur in the Pacific plate, and a LVZ is observed above the Pacific plate (at the base of the Philippine Sea plate) implying a relatively impermeable Philippine Sea (upper) plate. Uchida et al. [2009] interpret the low velocity material to represent hydrated upper mantle in the Philippine Sea plate owing to its high $V p / V s$ values. Conversely, no LVZ is observed where the North American plate overlies the subducting Pacific plate at the northern end of the Japan trench. Uchida et al. [2009] interpret the lack of a LVZ combined with abundant WBZ seismicity in the subducting Pacific plate as evidence of a permeable North American (upper) plate. Intriguingly, the LVZ and lower seismicity rate for the southern Japan subduction system are both associated with an upper plate that is oceanic, as is the Siletz terrane within the Oregon forearc, which also exhibits a LVZ [Audet et al., 2010] and a low seismicity rate.

[65] Well-constrained, seismic tomographic models of the Nankai subduction zone beneath southwest Japan indicate that high $V p / V s$ values are not restricted to hydrated oceanic crust. At depths of $25-35 \mathrm{~km}$ beneath the Tokai region, a high $V p / V s$ zone occurs in lower crust of the Eurasia continental plate and at depths of 30-45 km, a high $V p / V s$ zone occurs in the serpentinized mantle wedge of the Eurasia plate [Matsubara et al., 2008, 2009]. A high $V p / V s$ zone also occurs in oceanic crust of the subducting Philippine Sea plate [Matsubara et al., 2008, 2009]. Thus subsurface zones with high $V p / V s$ values have been observed not only in slab crust, but also in forearc lower crust, forearc upper mantle, and 


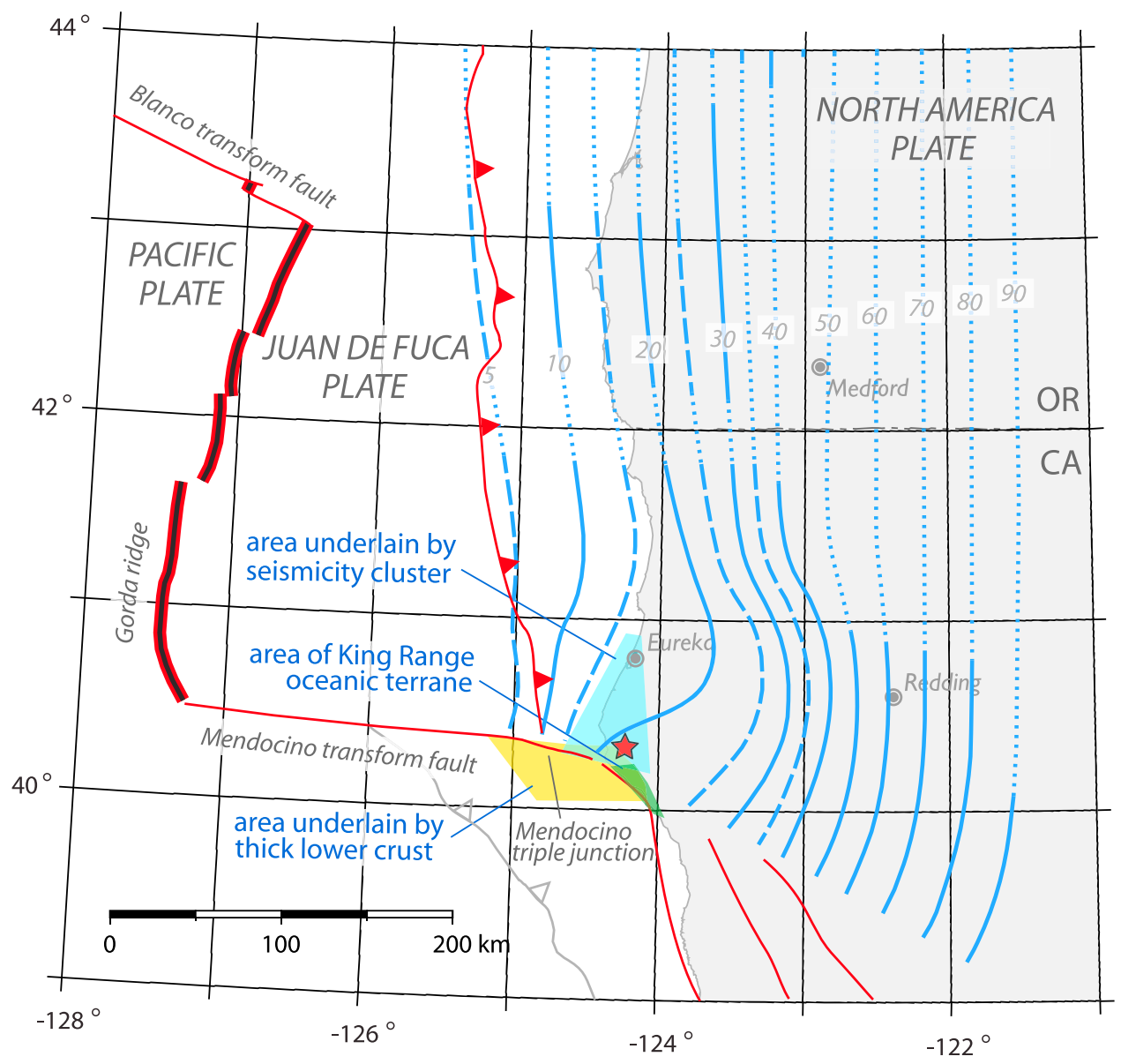

Figure 7. Map showing region with thickened lower crust [from Henstock and Levander, 2003] denoted by yellow polygon, accreted King Range oceanic terrane denoted by green polygon, and region of clustered seismicity above the Juan de Fuca plate denoted by cyan polygon. The 1992 M7.1 main shock epicenter is denoted by the red star.

the forearc mantle wedge. Our understanding of Cascadia earthquake occurrence would be improved if similar investigations are able to constrain the distribution of fluids in the slab and forearc.

\section{Relationship Between Forearc Structure and Earthquake Occurrence}

[66] Our slab model, combined with the improved spatial resolution of double-differenced earthquake relocations, offers new insights regarding subsurface seismic sources in the complex tectonic setting surrounding the Mendocino triple junction. The April 1992 M7.1 earthquake beneath northern California has previously been attributed to either slip along the subduction interface or slip along a similarly dipping surface a few kilometers above the plate interface [Oppenheimer et al., 1993]. Profiles of double-differenced seismicity through the main shock region resolve a DSZ which we have used to refine the location of the JdF plate (see discussion above) as well as the location of a distinctly separate cluster of seismicity about $10 \mathrm{~km}$ above the plate (Figure 6a). The Cape Mendocino earthquake resides within the overlying seismicity cluster (red star in Figure 6a). Furthermore, the cluster does not just represent aftershocks to the
M7.1 event, but has persisted through time. About half of the earthquakes within this cluster occurred within the year following the April 1992 event, but the remaining ones either occurred within the 17 years preceding April 1992 or the 17 years after April 1993 (Figure S6 in the auxiliary material). The M7.1 event initiated near the eastern edge of the seismicity cluster, consistent with observations that this earthquake ruptured updip [Oppenheimer et al., 1993], and its focal mechanism indicates shallow thrust motion (Figure 4b). We interpret this seismicity pattern to represent a blind thrust fault in the forearc above the plate interface.

[67] This interpretation requires a more complex slab geometry than previously proposed, in which the 1992 slip plane projects to the seafloor expression of the trench [Oppenheimer et al., 1993]. Specifically, just east of the trench our slab geometry dips somewhat steeply at about $15^{\circ}$, then flattens from slab depths of about 15 to $25 \mathrm{~km}$, before steepening again to about $25^{\circ}$ from $25 \mathrm{~km}$ depth to at least $45 \mathrm{~km}$, which is as deep as the slab can be tracked with hypocenters (Figure 6a). With this geometry, the seismicity cluster is located above the slab where it flexes concave upward in the transition from its initial moderate dip to a flat dip.

[68] Flat slabs are observed elsewhere around the Pacific Rim where the subducting plate is relatively buoyant as a 
result of its young age or thick oceanic crust. The Nazca plate beneath central Chile, for example, has an extended flat segment attributed to the buoyancy of thick oceanic crust associated with subduction of the Juan Fernandez ridge [Gutscher et al., 2000b; Yáñez et al., 2002]. Similarly subduction of the Cocos ridge beneath Costa Rica is associated with a flat slab segment [Gutscher et al., 2000a], whereas the Cocos slab beneath central Mexico has an extended flat portion [Pérez-Campos et al., 2008] attributed to its young age ( 16-13 Ma at the Mexico trench). The GDZ at the Cascadia trench is even younger ( $\sim 8-5$ Ma [Wilson, 2002]) than the Cocos plate and the initial slab warp is quite shallow (15-25 km deep), much shallower than the preceding examples. The low slab dip may reflect buckling resulting from oblique convergence with the Pacific plate.

[69] Double-differenced hypocenters delineating the seismicity cluster illuminate a triangular seismogenic structure (Figures $4 \mathrm{~b}$ and 7) approximately $80 \mathrm{~km}$ long in a N-S direction, up to $50 \mathrm{~km}$ long in an $\mathrm{E}-\mathrm{W}$ direction, and at least $8 \mathrm{~km}$ thick. We speculate that this tectonic element is a detached fragment of oceanic plate that did not subduct and has been stranded within the accretionary prism, similar perhaps to the fragment of Pacific plate stranded beneath central Japan [Toda et al., 2008] above the actively subducting Pacific plate. A more germane analog is found in the King Range, adjacent to the Mendocino triple junction, where late Cretaceous oceanic pillow basalts accreted to the North American margin within the past 15 My [McLaughlin et al., 1982].

[70] A $P$ wave seismic velocity model in the Mendocino triple junction region depicts an unusually thick subsurface layer with lower crustal velocities [Henstock and Levander, 2003] in the vicinity of the 1992 M7.1 main shock and aftershock sequence (Figure 7). Henstock and Levander [2003] assign the double-thick lower crustal layer to the Vizcaino terrane which transferred to the Pacific plate in the Miocene concurrent with the San Andreas transform boundary extending northward into this region [e.g., McCulloch, 1987; Leitner et al., 1998]. The Vizcaino terrane currently bounds the northwestern trace of the San Andreas fault system and may represent a fragment of the former Farallon plate which never subducted, instead detached and accreted to the now fossil accretionary margin. The Cascadia forearc contains similar discrete oceanic plate fragments such as the Siletz and Crescent terranes that accreted during demise of the Resurrection plate [Haeussler et al., 2003; McCrory and Wilson, 2010; Wilson and McCrory, 2010]. If additional plate fragments exist in the subsurface, they may release strain in significant earthquakes complicating our efforts to characterize earthquake hazards within the Cascadia subduction system.

\section{Summary}

[71] We have constructed a new model of JdF slab geometry by synthesizing depth information from earthquake locations and regional seismic velocity studies. Owing to variability in depth assignments both within and between data types, we implemented a modeling approach that gives highest weight to depths derived from hypoDD earthquake relocations and regional network earthquake locations. Even this comprehensive integration of available data leaves substantial uncertainties regarding the depth of the slab surface, reaching as much as $10 \mathrm{~km}$ in some areas, and it remains unclear whether the discrepancies reflect model uncertainties or reflect misidentification of subsurface structures. By documenting these discrepancies, we provide an initial step toward understanding their basis. However, resolving the source of discrepancies between velocity models will require additional geophysical research. Toward that goal, the currently deployed network of ocean-bottom seismometers (Cascadia GeoPRISMS) may improve seismic velocity models in the coastal and offshore regions, improve earthquake location accuracy, and lower detection thresholds.

[72] By separating earthquakes that occur in the forearc from those that occur in the slab, our new model reveals previously obscured details regarding the spatial distribution of earthquakes and their relationship to slab geometry. We propose that shallow slab earthquakes beneath Vancouver Island and northern California, as well as intermediate depth earthquakes beneath Washington, reflect increased fluid pressures that facilitate rupture arising from metamorphism of a hydrated JdF plate. Conversely, we propose that the lack of slab earthquakes beneath Oregon reflects anhydrous slab conditions in this region.

[73] The spatial pattern of earthquakes suggests additional processes promote or suppress earthquake occurrence. Slab and forearc earthquakes are largest and most abundant where the slab is undergoing internal deformation, near the Nootka fracture zone, along the slab kink south of Puget Sound, and near the Mendocino fracture zone. The abrupt southward shift from shallow- to intermediate-depth WBZ earthquakes, between 49 and $48^{\circ} \mathrm{N}$ correlates with a sharp increase in geodetic locking [e.g., McCaffrey, 2009], implying a change in plate boundary rheology associated with the slab arch. Some forearc earthquakes occur as isolated clusters above pseudo-faults in the JdF plate, perhaps arising from fluid migration between the slab and accretionary prism.

[74] The Cascadia accretionary margin contains subsurface structures that have the potential to create damaging earthquake sources within the forearc. We reinterpret the M7.1 Cape Mendocino earthquake to have ruptured a surface within the accretionary complex approximately $10 \mathrm{~km}$ above the JdF plate. We speculate that this earthquake is associated with a stranded fragment of former oceanic plate. Data collected by the Cascadia GeoPRISMS deployment may allow us to test this hypothesis.

[75] Acknowledgments. We thank Steve Kirby, Tom Parsons, George Spence, Mladen Nedimović, an anonymous reviewer, and an anonymous Associate Editor for careful reviews that improved this paper. Max Gardner constructed the animation which is available as auxiliary material. Earthquake catalog data were provided by the ANSS, CNSN, NCEDC, NCSS, and PNSN networks.

\section{References}

Audet, P., M. G. Bostock, D. C. Boyarko, M. R. Brudzinski, and R. M. Allen (2010), Slab morphology in the Cascadia forearc and its relation to episodic tremor and slip, J. Geophys. Res., 115, B00A16, doi:10.1029/ 2008JB006053.

Beaudoin, B. C., J. A. Hole, S. L. Klemperer, and A. M. Tréhu (1998), Location of the southern edge of the Gorda slab and evidence for an adjacent asthenospheric window-Results from seismic profiling and gravity, J. Geophys. Res., 103(B12), 30,101-30,115, doi:10.1029/98JB02231.

Bostock, M. G., R. D. Hyndman, S. Rondenay, and S. M. Peacock (2002), An inverted continental Moho and serpentinization of the forearc mantle, Nature, 417, 536-538, doi:10.1038/417536a. 
Calkins, J. A., G. A. Abers, G. Ekström, K. C. Creager, and S. Rondenay (2011), Shallow structure of the Cascadia subduction zone beneath western Washington from spectral ambient noise correlation, J. Geophys. Res., 116, B07302, doi:10.1029/2010JB007657.

Calvert, A. J., M. A. Fisher, K. Ramachandran, and A. M. Tréhu (2003), Possible emplacement of crustal rocks into the forearc mantle of the Cascadia Subduction Zone, Geophys. Res. Lett., 30(23), 2196, doi:10.1029 2003GL018541.

Calvert, A. J., K. Ramachandran, H. Kao, and M. A. Fisher (2006), Local thickening of the Cascadia forearc crust and the origin of seismic reflectors in the uppermost mantle, Tectonophysics, 420, 175-188, doi:10.1016/j.tecto.2006.01.021.

Calvert, A. J., L. A. Preston, and A. M. Farahbod (2011), Sedimentary underplating at the Cascadia mantle-wedge corner revealed by seismic imaging, Nat. Geosci., 4, 545-548, doi:10.1038/ngeo1195.

Cassidy, J. F. (1995), A comparison of the receiver structure beneath stations of the Canadian National Seismograph Network, Can. J. Earth Sci., 32(7), 938-951, doi:10.1139/e95-079.

Cassidy, J. F., and F. Waldhauser (2003), Evidence for both crustal and mantle earthquakes in the subducting Juan de Fuca plate, Geophys. Res. Lett., 30(2), 1095, doi:10.1029/2002GL015511.

Cassidy, J. F., G. C. Rogers, and F. Waldhauser (2000), Characterization of active faulting beneath the Strait of Georgia, British Columbia, Bull. Seismol. Soc. Am., 90(5), 1188-1199, doi:10.1785/0120000044.

Choy, G. L., and S. H. Kirby (2004), Apparent stress, fault maturity and seismic hazard for normal-fault earthquakes at subduction zones, Geophys. J. Int., 159(3), 991-1012, doi:10.1111/j.1365-246X.2004.02449.x.

Clowes, R. M., C. J. Yorath, and R. D. Hyndman (1987), Reflection mapping across the convergent margin of western Canada, Geophys. J. R. Astron. Soc., 89(1), 79-84, doi:10.1111/j.1365-246X.1987.tb04391.x.

Cozzens, B. D. (2011), A wider seismogenic zone at Cascadia due to hydrothermal circulation in subducting ocean crust, Msc thesis, 25 pp., N. M. Inst. of Min. and Technol., Socorro.

Creager, K. C., L. A. Preston, R. S. Crosson, T. Van Wagoner, A. M. Tréhu and the SHIPS-98 Working Group (2002), Three-dimensional reflection image of the subducting Juan de Fuca plate, U.S. Geol. Surv. Open File Rep., 02-328, 37-41.

Crosson, R. S., and T. J. Owens (1987), Slab geometry of the Cascadia subduction zone from earthquake hypocenters and teleseismic converted waves, Geophys. Res. Lett., 14, 824-827, doi:10.1029/ GL014i008p00824.

Dean, S. M., L. C. McNeill, T. J. Henstock, J. M. Bull, S. P. S. Gulick, J. A Austin Jr., N. L. B. Bangs, Y. S. Djajadihardja, and H. Permana (2010), Contrasting décollement and prism properties over the Sumatra 2004-2005 earthquake rupture boundary, Science, 329, 207-210, doi:10.1126/science. 1189373 .

Flück, P., R. D. Hyndman, and K. Wang (1997), Three-dimensional dislocation model for great earthquakes of the Cascadia subduction zone, J. Geophys. Res., 102(B9), 20,539-20,550, doi:10.1029/97JB01642.

Flueh, E. R., et al. (1998), New seismic images of the Cascadia subduction zone from cruise SO108-ORWELL, Tectonophysics, 293, 69-84.

Gerdom, M., A. M. Tréhu, E. R. Flueh, and D. Klaeschen (2000), The continental margin off Oregon from seismic investigations, Tectonophysics, 329(1-4), 79-97.

Graindorge, D., G. D. Spence, P. Charvis, J. Y. Collet, R. D. Hyndman, and A. M. Tréhu (2003), Crustal structure beneath the Strait of Juan de Fuca and southern Vancouver Island from seismic and gravity analyses, J. Geophys. Res., 108(B10), 2484, doi:10.1029/2002JB001823.

Gutscher, M.-A., R. Maury, J.-P. Eissen, and E. Bourdon (2000a), Can slab melting be caused by flat subduction?, Geology, 28(6), 535-538, doi:10.1130/0091-7613(2000)28<535:CSMBCB $>2.0 . \mathrm{CO} ; 2$

Gutscher, M.-A., W. Spakman, H. Bijwaard, and E. R. Engdahl (2000b), Geodynamics of flat subduction: Seismicity and tomographic constraints from the Andean margin, Tectonics, 19(5), 814-833, doi:10.1029/ 1999TC001152.

Hacker, B. R., G. A. Abers, and S. M. Peacock (2003a), Subduction factory: 1. Theoretical mineralogy, densities, seismic wave speeds, and $\mathrm{H} 2 \mathrm{O}$ contents, J. Geophys. Res., 108(B1), 2029, doi:10.1029/2001JB001127.

Hacker, B. R., S. M. Peacock, G. A. Abers, and S. Holloway (2003b), Subduction factory: 2. Are intermediate-depth earthquakes in subducting slabs linked to metamorphic dehydration reactions? J. Geophys. Res., 108(B1), 2030, doi:10.1029/2001JB001129.

Haeussler, P. J., D. W. Bradley, R. E. Wells, and M. L. Miller (2003), Life and death of the Resurrection plate: Evidence for its existence and subduction in the northeastern Pacific in Paleocene-Eocene time, Geol. Soc. Am. Bull., 15, 867-880.

Harris, R. A., H. M. Iyer, and P. B. Dawson (1991), Imaging the Juan de Fuca plate beneath southern Oregon using teleseismic P wave residuals, J. Geophys. Res., 96, 19,879-19,889, doi:10.1029/91JB02046.
Hasegawa, A., S. Horiuchi, and N. Umino (1994), Seismic structure of the northeastern Japan convergent margin: Synthesis, J. Geophys. Res., 99(B2), 22,295-22,311.

Hasegawa, A., J. Nakajima, S. Kita, T. Okada, T. Matsuzawa, and S. H. Kirby (2007), Anomalous deepening of a belt of intraslab earthquakes in the Pacific slab crust under Kanto, central Japan: Possible anomalous thermal shielding, dehydration reactions, and seismicity caused by shallower cold slab material, Geophys. Res. Lett., 34, L09305, doi:10.1029/ 2007GL029616.

Hayes, G. P., D. J. Wald, and R. L. Johnson (2012), Slab 1.0: A threedimensional model of global subduction zone geometries, J. Geophys. Res., 117, B01302, doi:10.1029/2011JB008524.

Henstock, T. J., and A. Levander (2003), Structure and seismotectonics of the Mendocino Triple Junction, California, J. Geophys. Res., 108(B5), 2260, doi:10.1029/2001JB000902.

Hirose, F., J. Nakajima, and A. Hasegawa (2008), Three-dimensional seismic velocity structure and configuration of the Philippine Sea slab in southwestern Japan estimated by double-difference tomography, J. Geophys. Res., 113, B09315, doi:10.1029/2007JB005274.

Hyndman, R. D. (1988), Dipping seismic reflectors, electrically conductive zones, and trapped water in the crust over a subducting plate, J. Geophys. Res., 93(B11), 13,391-13,405.

Hyndman, R. D., C. J. Yorath, R. M. Clowes, and E. E. Davis (1990), The northern Cascadia subduction zone at Vancouver Island-Seismic structure and tectonic history, Can. J. Earth Sci., 27, 313-329, doi:10.1139/ e90-030.

Igarashi, T., T. Matsuzawa, N. Umino, and A. Hasegawa (2001), Spatial distribution of focal mechanisms for interplate and intraplate earthquakes associated with the subducting Pacific plate beneath the northeastern Japan arc: A tripled-planed deep seismic zone, J. Geophys. Res., 106 2177-2191, doi:10.1029/2000JB900386.

Keach, R. W., II, J. E. Oliver, L. D. Brown, and S. Kaufman (1989), Cenozoic active margin and shallow Cascades structure: COCORP results from western Oregon, Geol. Soc. Am. Bull., 101, 783-794, doi:10.1130/ 0016-7606(1989)101<0783:CAMASC $>2.3 . \mathrm{CO} ; 2$.

Kirby, S. H. (1995), Interslab earthquakes and phase changes in subducting lithosphere, Rev. Geophys., 33, 287-297, doi:10.1029/95RG00353.

Kirby, S. H., E. R. Engdahl, and R. Denlinger (1996), Intermediate depth intraslab earthquakes and arc volcanism as physical expressions of crustal and uppermost mantle metamorphism in subducting slabs, in Subduction: Top to Bottom, Geophys. Monogr. Ser, vol. 96, edited by G. E. Bebout et al., pp. 195-214, AGU, Washington, D. C., doi:10. 1029/GM096p0195.

Kurtz, R. D., J. M. DeLaurier, and J. C. Gupta (1986), A magnetotelluric sounding across Vancouver Island detects the subducting Juan de Fuca plate, Nature, 321, 596-599, doi:10.1038/321596a0.

Leitner, B., A. M. Tréhu, and N. J. Godfrey (1998), Crustal structure of the northwestern Vizcaino block and Gorda escarpment, offshore northern California, and implications for post subduction deformation of a paleo accretionary margin, J. Geophys. Res., 103(B10), 23,795-23,812, doi:10.1029/98JB02050.

Lin, C.-H. (2011), Seismic evidence for possible slab melting from strong scattering waves, Terr. Atmos. Ocean. Sci., 22(3), 255-260, doi:10.3319/ TAO.2010.07.23.01(T)

Ma, L., R. S. Crosson, and R. S. Ludwin (1996), Focal mechanisms of western Washington earthquakes and their relationship to regional tectonic stress, in Assessing Earthquake Hazards and Reducing Risk in the Pacific Northwest, edited by A. M. Rogers et al., U.S. Geol. Surv. Prof. Pap., $1560,1,257-284$

Matsubara, M., K. Obara, and K. Kasahara (2008), Three-dimensional $\mathrm{P}$ - and S-wave velocity structure beneath the Japan Islands derived from the high-density seismic stations by seismic tomography, Tectonophysics, 454, 86-103, doi:10.1016/j.tecto.2008.04.016.

Matsubara, M., K. Obara, and K. Kasahara (2009), High-Vp/Vs zone accompanying non-volcanic tremors and slow-slip events beneath southwestern Japan, Tectonophysics, 472, 6-17, doi:10.1016/j.tecto.2008.06. 013

McCaffrey, R. (2009), Time-dependent inversion of three-component continuous GPS for steady and transient sources in northern Cascadia, Geophys. Res. Lett., 36, L07304, doi:10.1029/2008GL036784.

McCrory, P. A., and D. S. Wilson (2010), Origin of the Siletz terrane and its implications for the 3D structure of the Cascadia forearc, Abstract T12-C05 presented at 2010 Fall Meeting, AGU, San Francisco, Calif., 13-17 Dec.

McCrory, P. A., F. F. Pollitz, and J. L. Blair (2003), Evidence for a tear in the Juan de Fuca plate in the vicinity of the 2001 Nisqually earthquake, Eos Trans. AGU, 84(46), Fall Meet. Suppl., Abstract F1109.

McCrory, P. A., J. L. Blair, D. H. Oppenheimer, and S. R. Walter (2006), Depth to the Juan De Fuca Slab beneath the Cascadia Subduction 
Margin-A 3-D model for sorting earthquakes, U.S. Geol. Surv. Data Ser., 91. [Available at http://pubs.usgs.gov/ds/91/.]

McCulloch, D. S. (1987), The Vizcaino block south of the Mendocino triple junction, northern California, in Sedimentation and Evolution of the Eel River and Associated Basins of Northern California, edited by H. Schymiczek and R. Suchland, pp. 129-137, San Joaquin Geol. Soc., Bakersfield, Calif

McLaughlin, R. J., S. A. Kling, R. Z. Poore, K. McDougall, and E. D. Beutner (1982), Post-middle Miocene accretion of Franciscan rocks, northwestern California, Geol. Soc. Am. Bull., 93(7), 595-605, doi:10.1130/0016-7606(1982)93<595:PMAOFR $>2.0$. CO;2.

Michaelson, C. A., and C. S. Weaver (1986), Upper mantle structure from teleseismic $\mathrm{P}$ arrivals in Washington and northern Oregon, J. Geophys. Res., 91, 2077-2094, doi:10.1029/JB091iB02p02077.

Müller, R. D., M. Sdrolias, C. Gaina, and W. R. Roest (2008), Age, spreading rates and spreading symmetry of the world's ocean crust, Geochem. Geophys. Geosyst., 9, Q04006, doi:10.1029/2007GC001743.

Nabelek, J., X. Q. Li, S. Azevedo, J. Braunmiller, A. Fabritius, B. Leitner, A. M. Tréhu, and G. Zandt (1993), A high-resolution image of the Cascadia subduction zone from teleseismic converted phases recorded by a broadband seismic array, Eos Trans. AGU, 74(43), 431.

Nedimović M. R., R. D. Hyndman, K. Ramachandran, and G. D. Spence (2003), Reflection signature of seismic and aseismic slip on the northern Cascadia subduction interface, Nature, 424, 416-420, doi:10.1038/ nature 01840

Nedimović, M. R., S. M. Carbotte, A. J. Harding, R. S. Detrick, J. P. Canales, J. B. Diebold, G. M. Kent, M. Tischer, and J. M. Babcock (2005), Frozen magma lenses below the oceanic crust, Nature, 436, 1149-1152, doi:10.1038/nature03944.

Nedimović, M. R., D. R. Bohnenstiehl, S. M. Carbotte, J. P. Canales, and R. P. Dziak (2009), Faulting and hydration of the Juan de Fuca plate system, Earth Planet. Sci. Lett., 284, 94-102, doi:10.1016/j.epsl.2009.04.013.

Nicholson, T., M. Bostock, and J. F. Cassidy (2005), New constraints on subduction zone structure in northern Cascadia, Geophys. J. Int., 161, 849-859, doi:10.1111/j.1365-246X.2005.02605.x.

Oppenheimer, D. H., et al. (1993), The Cape Mendocino, California, earthquakes of April 1992: Subduction at the triple junction, Science, 261(5120), 433-438, doi:10.1126/science.261.5120.433.

Parsons, T. E., R. E. Wells, and M. A. Fisher (1999), Three-dimensional velocity structure of Siletzia and other accreted terranes in the Cascadia forearc of Washington, J. Geophys. Res., 104(B8), 18,015-18,039, doi:10.1029/1999JB900106.

Peacock, S. M., K. Wang, and A. M. McMahon (2002), Thermal structure and metamorphism of subducting oceanic crust-Insight into Cascadia intraslab earthquakes U.S. Geol. Surv. Open-File Rep., 02-328, 123-126.

Pérez-Campos, X., Y. H. Kim, A. Husker, P. M. Davis, R. W. Clayton, A. Iglesias, J. F. Pacheco, S. K. Singh, J. C. Manea, and M. Gurnis (2008), Horizontal subduction and truncation of the Cocos Plate beneath central Mexico, Geophys. Res. Lett., 35, L18303, doi:10.1029/ 2008GL035127.

Preston, L. A., K. C. Creager, R. S. Crosson, T. M. Brocher, and A. M Tréhu (2003), Intraslab earthquakes: Dehydrating the Cascadia slab, Science, 302, 1197-1200, doi:10.1126/science.1090751.

Ramachandran, K., S. E. Dosso, G. D. Spence, R. D. Hyndman, and T. M. Brocher (2005), Forearc structure beneath southwestern British Columbia: A three-dimensional tomographic velocity model, J. Geophys. Res., 110, B02303, doi:10.1029/2004JB003258.

Ramachandran, K., R. D. Hyndman, and T. M. Brocher (2006), Regional $\mathrm{P}$ wave velocity structure of the Northern Cascadia Subduction Zone, J. Geophys. Res., 111, B12301, doi:10.1029/2005JB004108.

Reyners, M., and D. Eberhart-Phillips (2009), Small earthquakes provide insight into plate coupling and fluid distribution in the Hikurangi subduction zone, New Zealand, Earth Planet. Sci. Lett., 282, 299-305, doi:10.1016/j.epsl.2009.03.034

Rietbrock, A., and F. Waldhauser (2004), A narrowly spaced doubleseismic zone in the subducting Nazca plate, Geophys. Res. Lett., 31 , L10608, doi:10.1029/2004GL019610.
Scholz, C. H. (1998), Earthquakes and friction laws, Nature, 391, 37-42, doi:10.1038/34097.

Smith, S. W., J. S. Knapp, and R. C. McPherson (1993), Seismicity of the Gorda plate, structure of the continental margin, and an eastward jump of the Mendocino triple juncion, J. Geophys. Res., 98, 8153-8171, doi:10.1029/93JB00026.

Spence, W. (1987), Slab pull and the seismotectonics of subducting lithosphere, Rev. Geophys., 25(9), 5-69.

Taber, J. J., and S. W. Smith (1985), Seismicity and focal mechanisms associated with the subduction of the Juan de Fuca plate beneath the Olympic Peninsula, Washington, Bull. Seismol. Soc. Am., 75(1), 237-249.

Toda, S., R. S. Stein, S. H. Kirby, and S. B. Bozkurt (2008), A slab fragment wedged under Tokyo and its tectonic and seismic implications, Nat. Geosci., 1, 771-776, doi:10.1038/ngeo318.

Tréhu, A. M., I. Asudeh, T. M. Brocher, J. H. Luetgert, W. D. Mooney, J. L. Nabelek, and Y. Nakamura (1994), Crustal architecture of the Cascadia forearc, Science, 266, 237-243, doi:10.1126/science.266.5183.237.

Uchida, N., J. Nakajima, A. Hasegawa, and T. Matsuzawa (2009), What controls interplate coupling?: Evidence for abrupt change in coupling across a border between two overlying plates in the NE Japan subduction zone, Earth Planet. Sci. Lett., 283, 111-121, doi:10.1016/j.eps1.2009.04. 003 .

Wada, I., S. Mazzotti, and K. Wang (2010), Intraslab stresses in the Cascadia subduction zone from inversion of earthquake focal mechanisms, Bull. Seismol. Soc. Am., 100(5A), 2002-2013, doi:10.1785/0120090349.

Waldhauser, F., and D. P. Schaff (2008), Large-scale relocation of two decades of northern California seismicity using cross-correlation and double-difference methods, J. Geophys. Res., 113, B08311, doi:10.1029/ 2007JB005479.

Wang, K., and G. C. Rogers (1994), An explanation for the double seismic layers north of the Mendocino Triple Junction, Geophys. Res. Lett., 21(2), 121-124, doi:10.1029/93GL03538.

Wannamaker, P. E., J. R. Booker, A. G. Jones, A. D. Chave, J. H. Filloux, H. S. Waff, and L. K. Law (1989), Resistivity cross section through the Juan de Fuca subduction system and its tectonic implications, J. Geophys. Res., 94(B10), 14,127-14,144, doi:10.1029/JB094iB10p14127.

Wessel, P., and D. Bercovici (1998), Interpolation with splines in tension: A Green's Function approach, Math. Geol., 30(1), 77-93, doi:10.1023/ A:1021713421882.

Wessel, P., and W. H. F. Smith (1998), New, improved version of the Generic Mapping Tools released, Eos Trans. AGU, 79, 579.

Williams, M. C., A. M. Tréhu, and J. Braunmiller (2011), Seismicity at the Cascadia Plate Boundary beneath the Oregon Continental Shelf, Bull. Seismol. Soc. Am., 101(3), 940-950, doi:10.1785/0120100198.

Wilson, D. S. (1989), Deformation of the so-called Gorda Plate, J. Geophys. Res., 94(B3), 3065-3075, doi:10.1029/JB094iB03p03065.

Wilson, D. S. (1993), Confidence intervals for motion and deformation of the Juan de Fuca Plate, J. Geophys. Res., 98(B9), 16,053-16,071, doi:10.1029/93JB01227.

Wilson, D. S. (2002), The Juan de Fuca plate and slab: Isochron structure and Cenozoic plate motions, U.S. Geol. Surv. Open File Rep., 02-328, 9-12.

Wilson, D. S., and P. A. McCrory (2010), A kinematic model for the formation of the Siletz terrane by capture of coherent fragments of the Farallon and Resurrection plates, Abstract T13C-2210 presented at 2010 Fall Meeting, AGU, San Francisco, Calif., 13-17 Dec.

Yáñez, G., J. Cembrano, M. Pardo, C. Ranero, and D. Selles (2002), The Challenger-Juan Fernández-Maipo major tectonic transition of the Nazca-Andean subduction system at 33- 34S: Geodynamic evidence and implications, J. South Am. Earth Sci., 15, 23-38, doi:10.1016/ S0895-9811(02)00004-4.

Zhao, D., K. Wang, G. C. Rogers, and S. M. Peacock (2001), Tomographic images of low P velocity anomalies above slab in northern Cascadia subduction zone, Earth Planet. Sci. Lett., 53(4), 285-293. 